NASA/TM—2009-215674

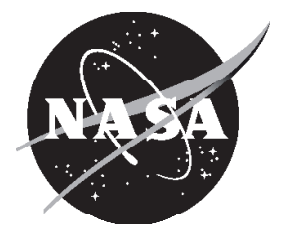

\title{
Development of Jet Noise Power Spectral Laws Using SHJAR Data
}

Abbas Khavaran

ASRC Aerospace Corporation, Cleveland, Ohio

James Bridges

Glenn Research Center, Cleveland, Ohio 


\section{NASA STI Program . . . in Profile}

Since its founding, NASA has been dedicated to the advancement of aeronautics and space science. The NASA Scientific and Technical Information (STI) program plays a key part in helping NASA maintain this important role.

The NASA STI Program operates under the auspices of the Agency Chief Information Officer. It collects, organizes, provides for archiving, and disseminates NASA's STI. The NASA STI program provides access to the NASA Aeronautics and Space Database and its public interface, the NASA Technical Reports Server, thus providing one of the largest collections of aeronautical and space science STI in the world. Results are published in both non-NASA channels and by NASA in the NASA STI Report Series, which includes the following report types:

- TECHNICAL PUBLICATION. Reports of completed research or a major significant phase of research that present the results of NASA programs and include extensive data or theoretical analysis. Includes compilations of significant scientific and technical data and information deemed to be of continuing reference value. NASA counterpart of peer-reviewed formal professional papers but has less stringent limitations on manuscript length and extent of graphic presentations.

- TECHNICAL MEMORANDUM. Scientific and technical findings that are preliminary or of specialized interest, e.g., quick release reports, working papers, and bibliographies that contain minimal annotation. Does not contain extensive analysis.

- CONTRACTOR REPORT. Scientific and technical findings by NASA-sponsored contractors and grantees.
- CONFERENCE PUBLICATION. Collected papers from scientific and technical conferences, symposia, seminars, or other meetings sponsored or cosponsored by NASA.

- SPECIAL PUBLICATION. Scientific, technical, or historical information from NASA programs, projects, and missions, often concerned with subjects having substantial public interest.

- TECHNICAL TRANSLATION. Englishlanguage translations of foreign scientific and technical material pertinent to NASA's mission.

Specialized services also include creating custom thesauri, building customized databases, organizing and publishing research results.

For more information about the NASA STI program, see the following:

- Access the NASA STI program home page at http://www.sti.nasa.gov

- E-mail your question via the Internet to help@ sti.nasa.gov

- Fax your question to the NASA STI Help Desk at $443-757-5803$

- Telephone the NASA STI Help Desk at 443-757-5802

- Write to: NASA Center for AeroSpace Information (CASI) 7115 Standard Drive Hanover, MD 21076-1320 
NASA/TM-2009-215674

AIAA-2009-3378

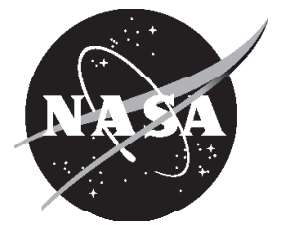

\section{Development of Jet Noise Power Spectral Laws Using SHJAR Data}

Abbas Khavaran

ASRC Aerospace Corporation, Cleveland, Ohio

James Bridges

Glenn Research Center, Cleveland, Ohio

Prepared for the

15th Aeroacoustics Conference (30th AIAA Aeroacoustics Conference)

sponsored by the American Institute of Aeronautics and Astronautics, CEAS

Miami, Florida, May 11-13, 2009

National Aeronautics and

Space Administration

Glenn Research Center

Cleveland, Ohio 44135 


\section{Acknowledgments}

Support from the Subsonic Fixed Wing and Supersonic Projects under the Fundamental Aeronautics Program is greatly appreciated.

This report is a formal draft or working paper, intended to solicit comments and ideas from a technical peer group.

This work was sponsored by the Fundamental Aeronautics Program at the NASA Glenn Research Center.

Level of Review: This material has been technically reviewed by technical management.

Available from

NASA Center for Aerospace Information 7115 Standard Drive

Hanover, MD 21076-1320
National Technical Information Service 5285 Port Royal Road Springfield, VA 22161 


\title{
Development of Jet Noise Power Spectral Laws Using SHJAR Data
}

\author{
Abbas Khavaran \\ ASRC Aerospace Corporation \\ Cleveland, Ohio 44135 \\ James Bridges \\ National Aeronautics and Space Administration \\ Glenn Research Center \\ Cleveland, Ohio 44135
}

\begin{abstract}
High quality jet noise spectral data measured at the Aeroacoustic Propulsion Laboratory at the NASA Glenn Research Center is used to examine a number of jet noise scaling laws. Configurations considered in the present study consist of convergent and convergent-divergent axisymmetric nozzles. Following the work of Viswanathan, velocity power factors are estimated using a least squares fit on spectral power density as a function of jet temperature and observer angle. The regression parameters are scrutinized for their uncertainty within the desired confidence margins. As an immediate application of the velocity power laws, spectral density in supersonic jets are decomposed into their respective components attributed to the jet mixing noise and broadband shock associated noise. Subsequent application of the least squares method on the shock power intensity shows that the latter also scales with some power of the shock parameter $\left(M_{j}^{2}-M_{d}^{2}\right)$. A modified shock parameter is defined in order to reduce the dependency of the regression factors on the nozzle design point within the uncertainty margins of the least squares method.
\end{abstract}

\section{Nomenclature}

$A$

$B$

$c$

$D$

$f$

$H e=f D / c_{\infty}$

$M=U / c$

$M_{j}=U_{j} / c_{j}$

$M_{a}=U / c_{\infty}$

$m$

$n$

$p$

$p_{\text {ref }}$

$P S D=10 \log \left(\overline{p^{2}} U_{j} / p_{r e f}^{2} D\right)$ $S t=f D / U_{j}$

$T$

$U$

$U_{j}$
Jet area

Intercept parameter

Sound speed

Jet exit diameter (ft)

Frequency $(\mathrm{Hz})$

Helmholtz number

Aerodynamic Mach number

Ideally expanded Mach number

Acoustic Mach number

Shock intensity power factor

Velocity power factor

Acoustic pressure

Acoustic reference pressure $(0.0002 \mu \mathrm{bar})$

Power spectral density per Strouhal number, $\mathrm{dB}$

Strouhal number based on ideally expanded jet velocity

Temperature ratio - normalized relative to ambient temperature

Jet speed (fps)

Ideally expanded jet speed (fps) 
Shock intensity parameter

Specific heat ratio

$\theta$

Polar angle from jet inlet

$\chi$

Goodness factor

$\begin{array}{ll}\text { Subscripts } & \\ d & \text { Design point } \\ e & \text { Nozzle exit } \\ j & \text { Fully expanded condition } \\ s & \text { Static condition } \\ t & \text { Total or stagnation point } \\ \infty & \text { Ambient conditions }\end{array}$

\subsection{Introduction}

Development of a system level design and optimization tool is essential to the technology needs of the future commercial aircraft. As required by NASA's Fundamental Aeronautics program, high fidelity design and analysis tools need to be developed to enable an optimal balance of performance, noise and emissions - and a rapid progression of new concepts and technology. Basic research is conducted within each discipline to gain an understating of the fundamentals, and to reduce uncertainty in modeling. Application of new technology to design efficient and environmentally friendly engines is an integral element of both Subsonic Fixed Wing and Supersonics projects. This article describes an ongoing activity in support of the environmental goals related to noise emission.

Development of a successful analytical tool in jet noise prediction relies heavily on quality data. A typical narrowband spectrum in jet noise could consist of three distinct components, the jet mixing noise, shock-associated noise and screech. As the jet exit velocity becomes supersonic (relative to the ambient conditions), the mixing noise could be complemented by an additional component at small aft angles that is caused by the instabilities of the mean flow. From a modeling standpoint, it is extremely helpful if one succeeds in dividing the spectrum into components that are attributed to various generation mechanisms.

The usual procedure is to start with a jet operating condition subject to a single generation mechanism. If one can propose scaling laws for this particular noise component, then it might be possible, with various degrees of success, to subtract that component from a multi-component spectrum. For example, shock-associated noise is obtained when we subtract the mixing noise from the total noise. Jet noise measurements are normally displayed as the power spectral density (PSD) per normalized frequency parameter, and are herein referred to as the total noise. When multiple sources are present, they are usually regarded as completely incoherent, and in the acoustic far field, the PSD of the sum is related to the components as $10^{P S D / 10}=10^{P S D_{1} / 10}+10^{P S D_{2} / 10}$.

In aeroacoustics, the most quoted scaling law is the $U^{8}$ power law derived from Lighthill's acoustic analogy (Ref. 1), as described in great detail in Reference 2. It concludes that the acoustic power emitted over the surface of a large sphere surrounding a jet is proportional to the eight-power of the jet exit velocity. Other attempts to fine-tune the power law (Refs. 3 to 5) consider the integrated power spectral density (i.e., the overall sound pressure level (OASPL) at each angle) to depend on both angle and jet temperature. Following the work of Viswanathan (Ref. 3), velocity power factors are evaluated from the narrowband data gathered at the Small Hot Jet Acoustic Rig (SHJAR) at the NASA Glenn Research Center, applying a least squares fit on the OASPL as a function of jet temperature and observer angle. The goodness of the fit is studied at each angle, and alternative relationships are proposed that improve the spectral collapse when certain conditions are met. 
Since we use the integrated spectrum as the dependent variable in a linear regression, the PSD curve scales successfully from one jet to another only when (1) the basic shape of the spectrum is preserved, (2) the normalized frequency parameter meets the shift requirements. It will be noted that these two conditions are not always met at aft angles. However, it is possible to select a new normalized frequency parameter and collapse a major segment of the scaled spectra as long as the acoustic Mach number remains subsonic.

Supersonic jets at imperfectly expanded condition emit broadband shock associated noise (BBSN) in addition to the jet mixing noise. In many cases, shock noise is accompanied with screech. Under some conditions (unheated jets in particular) the screech tones can be very strong and result in broadband amplification noise (AMN). This amounts to an additional 3 to $5 \mathrm{~dB}$ noise enhancement throughout the spectrum. Excitation of a jet by a pure tone has been established experimentally and there are indications that this amplification happens at sideline as well as small aft angles (Refs. 6 to 8). It is shown that scaling laws help identify the amplification. When intensity scaling is extended to BBSN, it makes a difference whether this amplification is added to the mixing noise prior to subtraction from the total noise, or if it is simply considered as an element of the shock noise. In the former approach, the mixing noise is increased uniformly and is matched with the total noise at the early part of the spectrum. In the latter approach, the unmatched mixing noise is subtracted from the total noise to obtain the BBSN.

The paper is organized in the following order. Section 1.1 briefly describes the SHJAR experimental setup. In Section 2, we apply the linear least squares regression to find the velocity power factors for the jet mixing noise. The goodness of the fit, the joint confidence region of the two regression parameters, and their marginal inference interval is discussed at selective angles. Section 3 applies the scaling laws to a host of nozzles at various operating conditions and evaluates the quality of the spectral collapse at different angles and Mach numbers. The utility of the scaling laws are shown in Section 4 when we examine various noise components. In particular, the scaling laws are extended to the broadband shock associated noise and shock intensity parameters are examined versus angle and temperature.

\subsection{Experimental Setup}

Hot and cold jet noise spectral data have been acquired within the Small Hot Jet Acoustic Rig for an extensive test matrix. The SHJAR is a single stream hot jet rig located within the AeroAcoustic Propulsion Laboratory (AAPL) at the NASA Glenn Research Center. It uses remotely located compressors and a hydrogen burning combustor to provide heated air to test-nozzles at temperatures up to $1300{ }^{\circ} \mathrm{F}$ and at pressures up to $150 \mathrm{psi}$. Additional noise generated by flow through piping and control valves is removed using a baffled muffler, and the flow is conditioned using screens to create clean and quiet conditions at the nozzle exit. Acoustic data repeatability has been determined to be within $0.50 \mathrm{~dB}$ in one-third octave bands at all frequencies (Refs. 9 to 12).

The AAPL, which houses the SHJAR, is a 65-ft-geodesic dome lined with 24-in.-long sound absorbing wedges which remove sound reflection at all frequencies above $200-\mathrm{Hz}$ and provide the anechoic environment required for noise studies. The floor and all surfaces around SHJAR are covered with fiberglass wedges (Fig. 1.1). The jet exhaust from SHJAR is directed outside through a large door. Additional details about the facility are provided in References 9 and 10.

For most testing, SHJAR uses a 2.0 in nozzle, but can also operate larger nozzles with some limitation on cold set points at high Mach number. In typical testing, the SHJAR can cover a range of Mach numbers up to Mach 2.0, and static temperature ratios up to 2.8 using a hydrogen combustor and central air compressor facilities. Stagnation flow conditions for the rig are measured within a 24 in. plenum upstream of the nozzle.

Nozzles used in the present noise measurements are designated as smcxxx, where "xxx" is a 3 digit number that identifies a particular nozzle (Table 1.1). The smc000 is a baseline convergent nozzle with a $5^{\circ}$ conic contraction and a 0.04 -in.-thick lip (Fig. 1.2), and smc021 is a modified smc000 geometry in order to minimize the screech noise (Fig. 1.3). In addition to the data repeatability, SHJAR measurements 


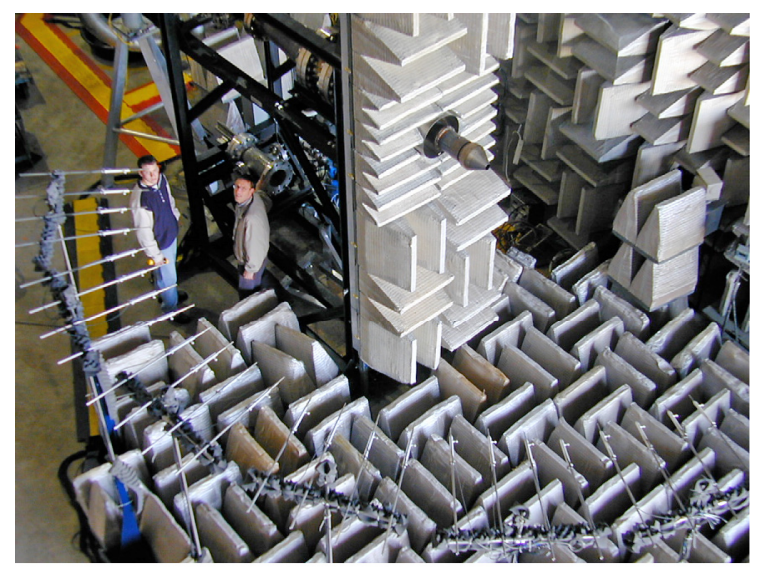

Figure 1.1.-Small Hot Jet Acoustic Rig (SHJAR).

TABLE 1.1 NOZZLE CONFIGURATIONS TESTED IN SHJAR FACILITY

\begin{tabular}{|l|c|c|c|c|}
\hline Nozzle & Configuration & $M_{d}$ & $D_{e}-$ in. & $\mathrm{NPR}_{\mathrm{d}}$ \\
\hline smc000 & Convergent & 1.00 & 2.0 & 1.89 \\
smc021 $^{\text {a }}$ & Convergent & 1.00 & 2.0 & 1.89 \\
smc014 $_{\text {smc015 }}$ & $\mathrm{CD}$ & 1.185 & 2.0 & 2.37 \\
smc016 & $\mathrm{CD}$ & 1.40 & 2.0 & 3.18 \\
smc018 & $\mathrm{CD}$ & 1.50 & 2.0 & 3.67 \\
\end{tabular}

${ }^{\mathrm{a} C}$ Convergent nozzle with reduced screech.

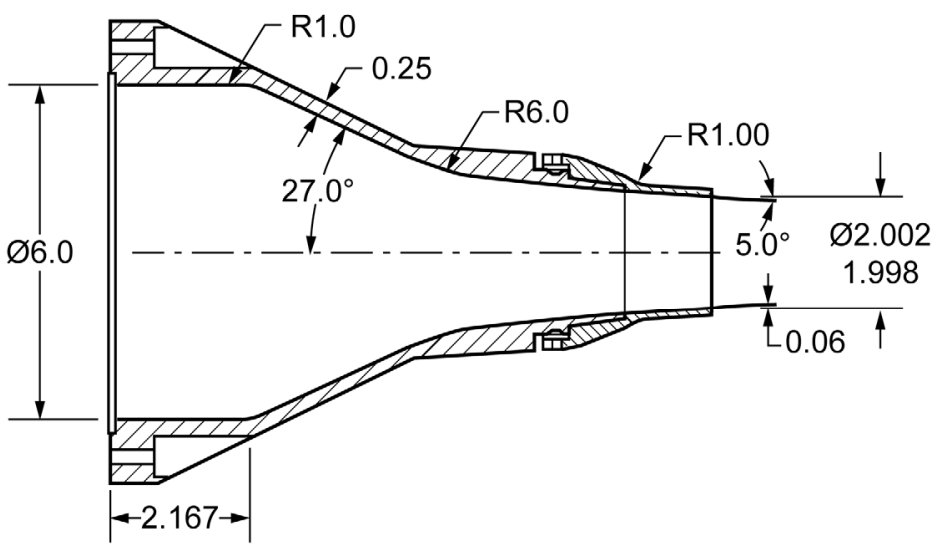

Figure 1.2.-Convergent nozzle smc000.

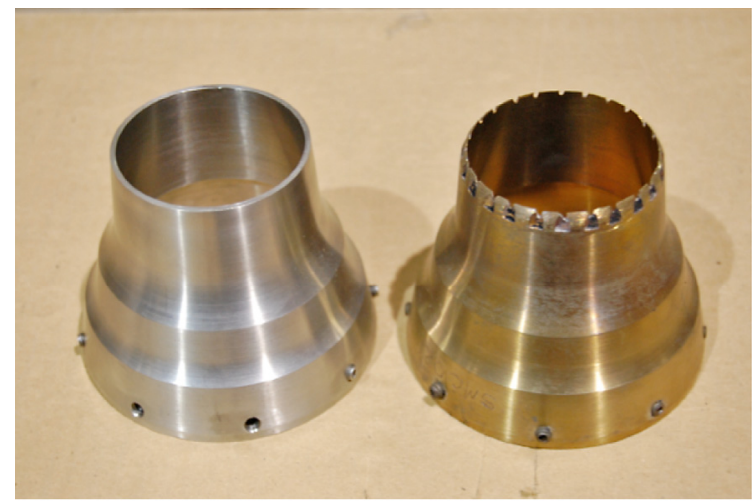

Figure 1.3.—smc000 and smc021 nozzles.

have also been examined versus other existing measurements (Refs. 3, 13 to 17) in order to identify possible extraneous sources that are unrelated to jet noise.

Measurements are based on a test matrix designed to isolate various parameters that are thought to drive the physics of noise generation and its propagation such as constant jet velocity and constant temperature (static or stagnation). For jets operating at a pressure ratio larger than 1.89, i.e., ideal Mach number $>1.0$, convergent-divergent nozzles were designed for ideal expansion and were tested at different temperatures. The result is a matrix of data at fixed acoustic Mach number $M_{a}$, aerodynamic Mach number $M$ and temperature ratio $T$ for a broad range of conditions, with and without screech and broadband shock-associated noise.

\subsection{Mixing Noise and Velocity Power Factors}

Power laws for the jet mixing noise are derived from a matrix of test cases that are free of shockassociated noise. A convergent nozzle (i.e., smc000, Table 1.1) operating at a nozzle pressure ratio (NPR) $<1.89$ is considered for this purpose (NPR is defined as the total plenum pressure divided by the ambient static pressure). A set of $N$ test cases is tabulated at a constant static or stagnation temperature (Ref. 5), where each case corresponds to an exit velocity $U_{i}, i=1,2, \ldots, N$. Measurements are reported on a 100diameter (200 in) arc, and at 24 equally spaced angles $\theta\left(50^{\circ}\right.$ to $165^{\circ}$ relative to the nozzle inlet), and have been corrected for atmospheric attenuation. 
The integrated spectrum (i.e., the overall sound pressure level OASPL) at each jet velocity $U_{i}$ is

$$
\hat{y}_{i}=\operatorname{OASPL}(\theta, T), \quad i=1,2, \ldots, N
$$

The integration is carried out in a narrowband, and within a fixed Strouhal frequency range of $0.02 \leq S t \leq 10.0$ after removing possible extraneous facility noise at either low or high end of the spectrum. Using a linear least squares method, we define a line-fit

$$
y_{i}=n(\theta, T) x_{i}+B(\theta, T) ; \quad x_{i}=10 \log \left(U_{i} / c_{\infty}\right), \quad i=1,2, \ldots, N
$$

$n$ and $B$ are referred to as the velocity power factor and the intercept parameter respectively. The intercept parameter $B$ is the same as the approximated overall sound pressure level directivity (OASPL) at temperature $T$ if the exit acoustic Mach number were 1.0. Subsequently the effect of the arc distance on noise is included in parameter $B$. As pointed out earlier, all measurements presented here are at an arc distance of $100 D$ and are corrected for the atmospheric attenuation.

Let the uncertainty at each data point be $\sigma_{i}$, then the measure of goodness of the fit is defined as

$$
\chi(\theta, T)=\frac{1}{N-2} \sum_{i=1}^{N} \frac{\left(\hat{y}_{i}-y_{i}\right)^{2}}{\sigma_{i}} .
$$

We require $N$ to be at least 3. Additionally, all experimental data are considered to have equal uncertainty $\left(\sigma_{i}=1\right)$. Other statistical properties of the linear fit such as confidence intervals for regression parameters $\mathrm{n}$ and $\mathrm{B}$ and their joint confidence region (Ref. 18) are also examined at selective angles.

When the regression errors are within acceptable bounds, we extrapolate the scaling laws to the jet mixing noise from supersonic jets. A Scaled PSD is defined once we remove the extra dB associated $U_{j}^{n}$ from each jet

$$
\text { scaled PSD } \equiv P S D-10 n(\theta, T) \log \left(U_{j} / c_{\infty}\right)-10 \log \left(A_{j} / A_{e}\right)
$$

The scaled spectra are now expected to collapse in amplitude across different jets, including supersonic jets. As stated earlier, the normalized frequency parameter and the basic shape of the PSD curve need to meet certain requirements for the collapse to be successful. The last term on the right hand side of Eq. 2.4 signifies that in imperfectly expanded supersonic jets, a fully expanded velocity $U_{j}$ is reached at an area $A_{j}$ that is different from the exit area $A_{e}$. Overexpanded jets reach full expansion prior to the nozzle exit, while underexpand jets reach a fully expanded jet velocity downstream of the exit plane. When supersonic jets are operating at off-design conditions, the mismatch between the exit static pressure $p_{e}$ and the ambient pressure $p_{\infty}$ results in the shock formation. If the associated entropy change is considered small enough to permit an isentropic flow relation $p / \rho^{\gamma}=$ const, then the fully expanded area $A_{j}$ is estimated as 


$$
\begin{aligned}
& \frac{p_{e}}{p_{\infty}}=\left(\frac{1+M_{j}^{2}(\gamma-1) / 2}{1+M_{d}^{2}(\gamma-1) / 2}\right)^{\frac{\gamma}{\gamma-1}}, \\
& \frac{A_{j}}{A_{e}}=\frac{M_{d}}{M_{j}}\left(\frac{p_{e}}{p_{\infty}}\right)^{\frac{\gamma+1}{2 \gamma}}
\end{aligned}
$$

where $M_{j}$ is the fully expanded Mach number, and $M_{d}$ is the design Mach number. In addition, the usual onedimensional compressible flow relations hold between the nozzle pressure ratio NPR, Mach number $M_{j}$ and the corresponding static temperature $T_{\mathrm{s}}$

$$
\begin{gathered}
N P R=\left(1+\frac{\gamma-1}{2} M_{j}^{2}\right)^{\frac{\gamma}{\gamma-1}} . \\
T_{t} / T_{s}=N P R^{\frac{\gamma-1}{\gamma}} .
\end{gathered}
$$

Using the convergent nozzle smc000, a host of SHJAR test points at subsonic conditions (i.e., NPR $<1.89$ ) were grouped according to static temperature $T_{s}=1.0,1.20,1.43,1.76,2.27,2.70$. Within the first two groups (i.e., $T_{s}=1.0,1.20$ ), jets were confined to subsonic acoustic Mach numbers, while the latter four groups consisted of jets at both subsonic and supersonic acoustic Mach numbers. The result of the least squares fit is usually displayed as a set of parametric curves for regression parameters $n\left(\theta, T_{s}\right)$ and $B\left(\theta, T_{s}\right)$ as in Figure 2.1. The outcome is expected to be sensitive to the number of test points in each group and the range of the dependent variable $x_{i}$. Detailed listings of the set points and the sensitivity analysis of the regression parameters are provided in Reference 5. Figure 2.2(a) shows the goodness
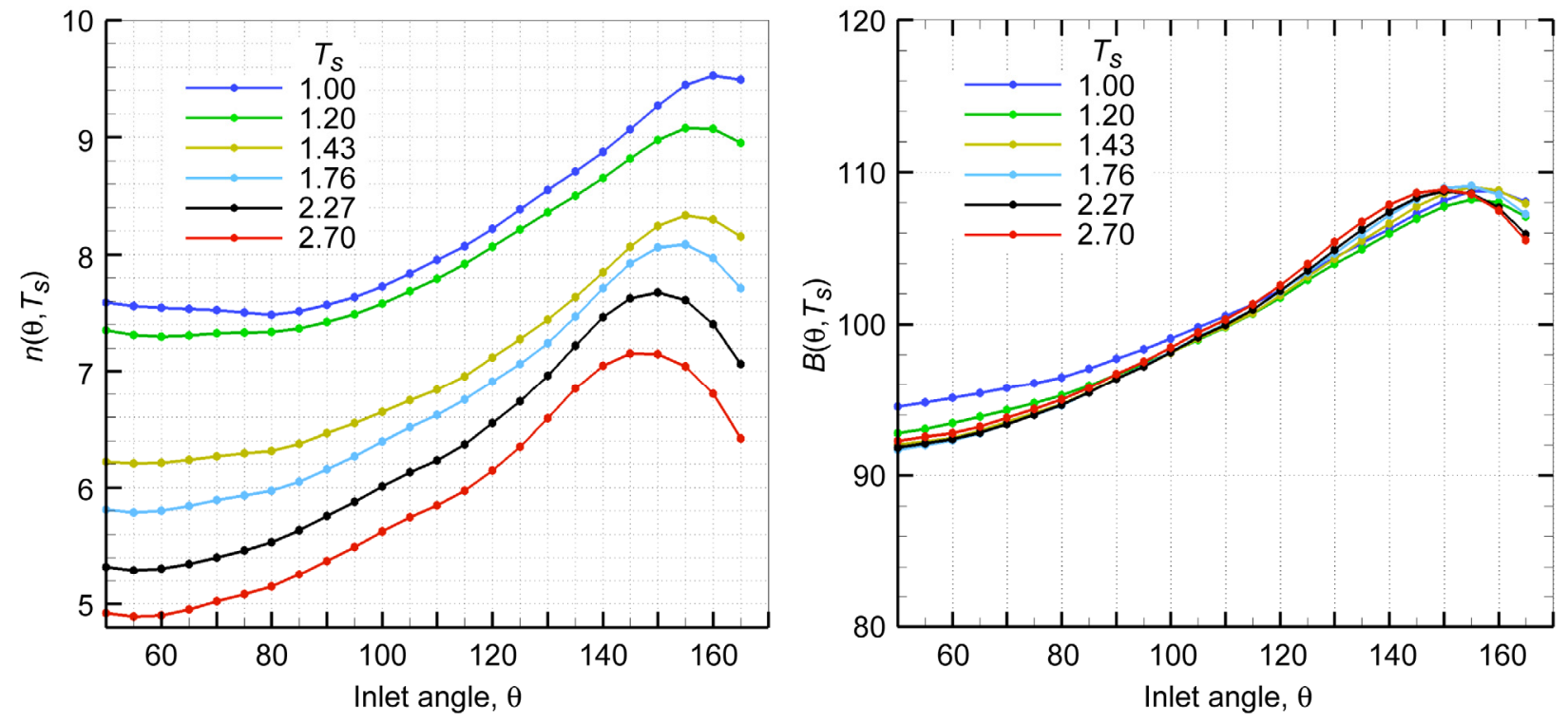

Figure 2.1.-Velocity power factor $n$ and the intercept parameter $B$ as a function of angle and static temperature. 

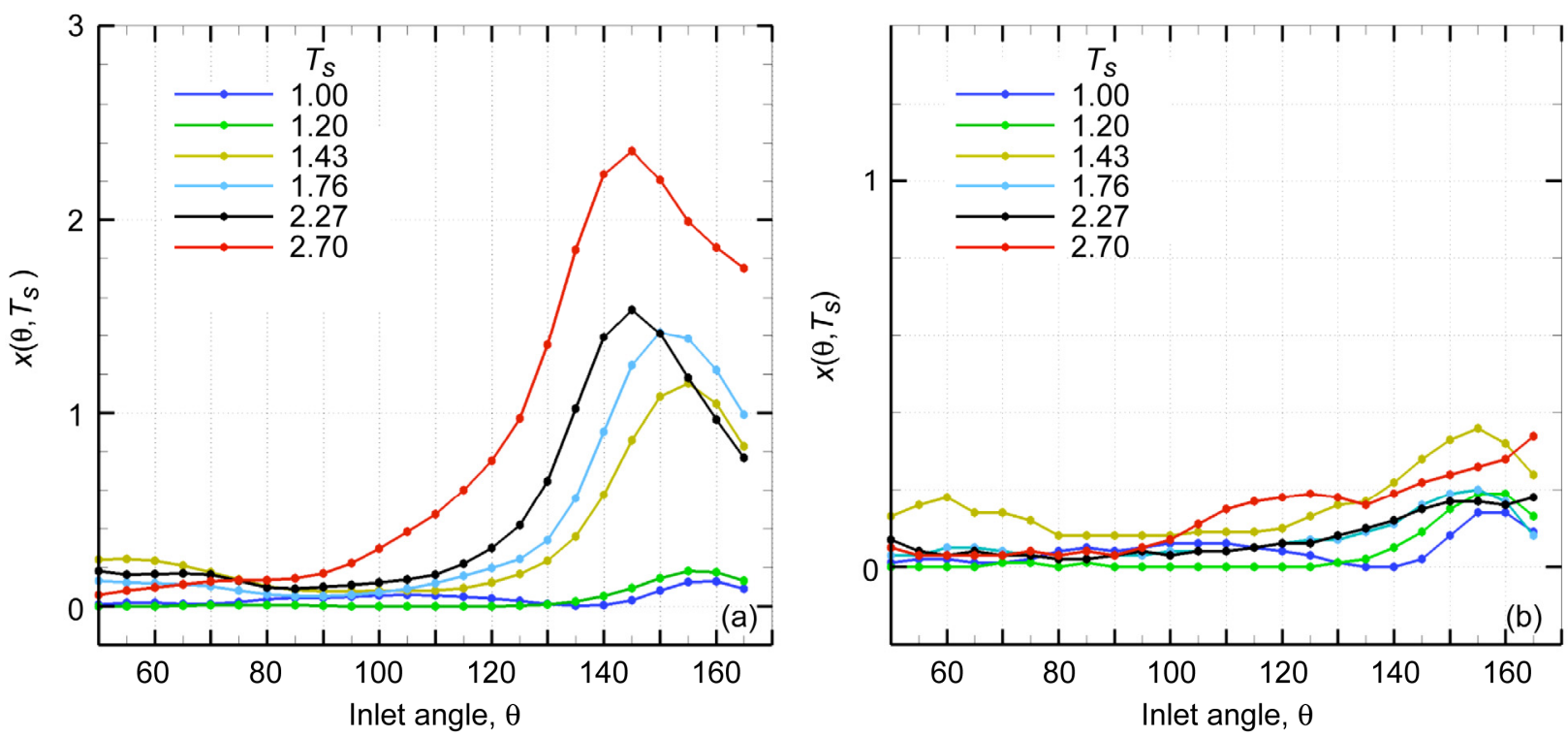

Figure 2.2-(a) Goodness factor for the regression parameters of Figure 2.1. (b) Goodness of the fit if the regression were limited to points at subsonic acoustic Mach number only.
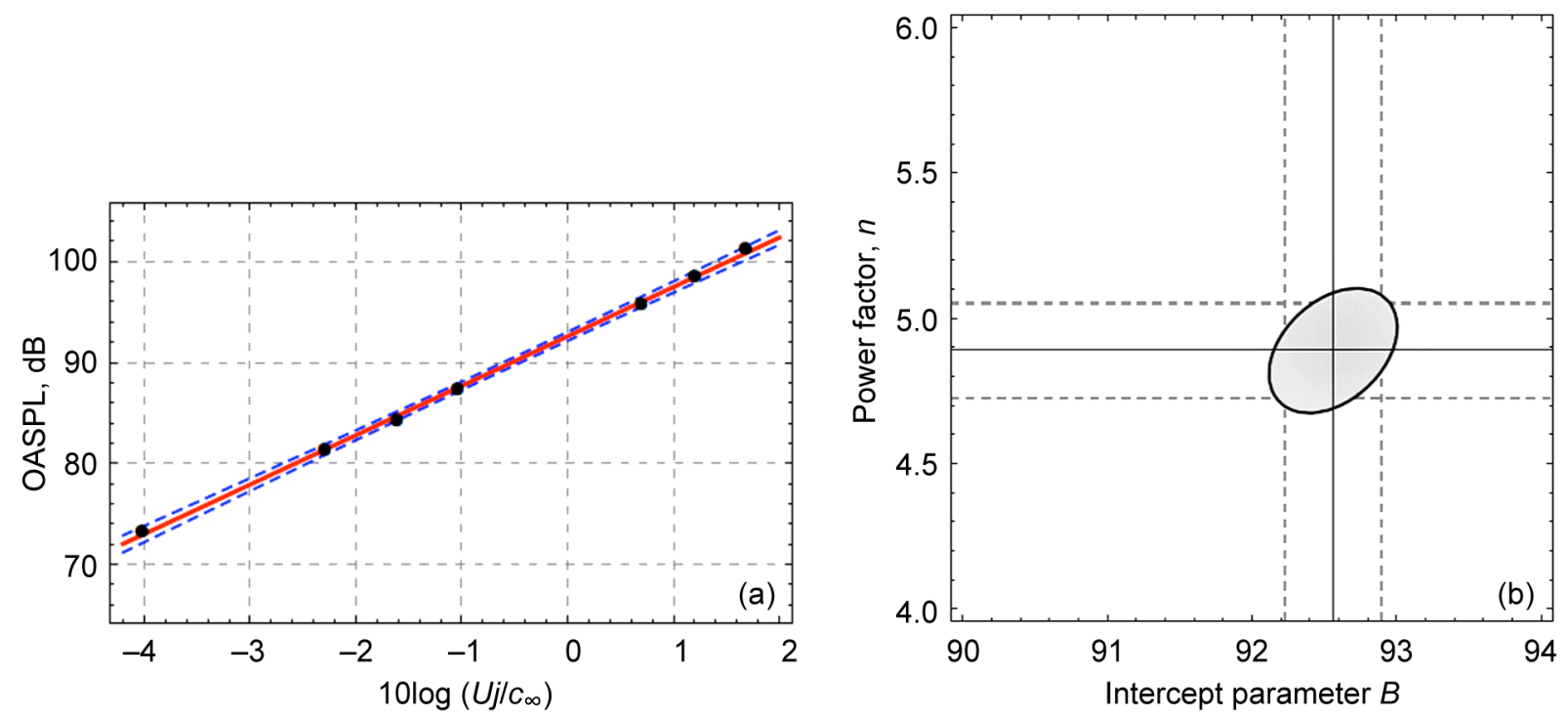

Figure 2.3-(a) Measurements (symbols); least squares fitted line (red); and the 95\% confidence band (dashed lines). (b) Joint $95 \%$ confidence region (ellipsoid) and marginal inference intervals (dashed lines) of parameters $n$ and $B$. $\left(T_{S}=2.70, \theta=60^{\circ}\right)$

factor corresponding to Figure 2.1. A small goodness factor is indicative of a successful regression. When data variance is relatively large (as in Fig 2.2(a) $\theta \geq 120^{\circ}$ ), the addition of new set points to the group does not necessarily improve the linear regression. However, if set points were to be confined to $M_{a}<1$, then data scatter would remain small at all angles as shown in Figure 2.2(b).

To examine the confidence band of the interpolation parameters, consider the measurements at $T_{s}=2.70$, where 7 points $\left(0.39<M_{a}<1.47\right)$ have been utilized in the regression. Figure 2.3(a) shows the regression points, the least squares fit (red line) and the 95 percent confidence margin at $60^{\circ}$. The joint confidence region (Ref. 18) falls within $n=4.89 \pm 0.17$ and $B=92.56 \pm 0.33$ as seen in Figure 2.3(b). The error band is usually expected to decrease with increasing the number of regression points. However, this 

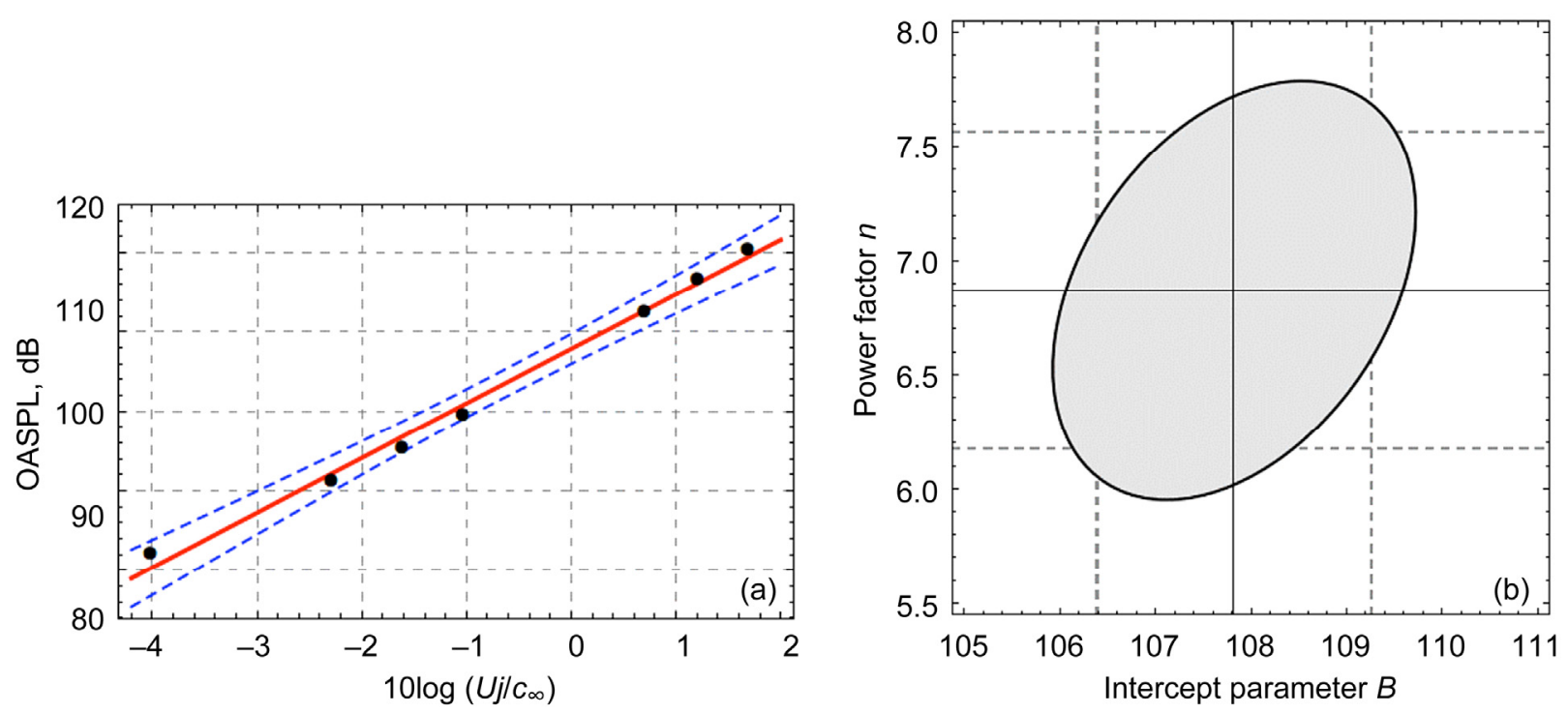

Figure 2.4-(a) Measurements (symbols); least squares fitted line (red); and the $95 \%$ confidence band (dashed lines). (b) Joint $95 \%$ confidence region (ellipsoid) and marginal inference intervals (dashed lines) of parameters $n$ and $B .\left(T_{S}=2.70, \theta=160^{\circ}\right)$

is not true at small aft angles where the range of the dependent variable $x_{i}$ plays a more instrumental role due to the increased scatter at $M_{\mathrm{a}}>1$. For example at $\theta=150^{\circ}$, six interpolation points with $M_{\mathrm{a}}<1$ generates a much better fit compared to 8 points at both $M_{\mathrm{a}}<1$ and $M_{\mathrm{a}}>1$.

Shown in Figure 2.4 is the 95 percent confidence band of the two parameters at $160^{\circ}$. The joint confidence region is now increased to $n=6.87 \pm 0.70$, and $B=107.82 \pm 1.48$. The above error estimates point to the deteriorating quality of the linear regression method at aft angles. It will be shown that changes in the spectral shape with jet speed at aft angles make it increasingly difficult to obtain a satisfactory spectral collapse throughout the frequency range at all speeds. However, the regression parameters $n$ and $B$ in Figure 2.1 could still be employed to collapse, at least, a major segment of the subsonic data at aft angles.

\subsection{Examination of Jet Noise Spectral Data Using Velocity Power Factors}

In order to equip us with the necessary tools to examine the jet noise power spectral laws, additional charts for the regression parameters $n$ and $B$ are evaluated as a function of angle and stagnation temperature. Figure 3.1 shows such a template when interpolation consisted of 5 points with subsonic aerodynamic Mach number at each temperature. Details of the error analysis with and without points at supersonic acoustic Mach number are given in Reference 5. Conclusions are similar to those stated in the previous section and show a gradual decline in the quality of the regression fit at aft angles. Since parameter $B$ measures the OASPL directivity at $M_{a}=1.0$ where the two temperatures convert as $T_{t}=T_{s}+(\gamma-1) / 2$, then a one-to-one relationship exists between the two intercept parameters at related temperatures. A parallel correspondence is not possible between the two $n$ factors because velocity cannot be held constant in order to convert temperatures.

According to Figure 3.1(b), parameter $B$ appears to collapse at the three higher stagnation temperatures of 1.8, 2.2 and 2.7-subsequently velocity scaling of jet noise across such temperatures is achieved with a single parameter. Lower temperature jets, on the other hand, show slight decrease in parameter $B$ with increasing temperature (Fig. 2.1(b) at static temperatures of 1.0 and 1.20), subsequently both parameters $n$ and $B$ would be required for a successful scaling regardless of which temperature is used. The major difference between the two temperatures relates to approximations made in defining a 

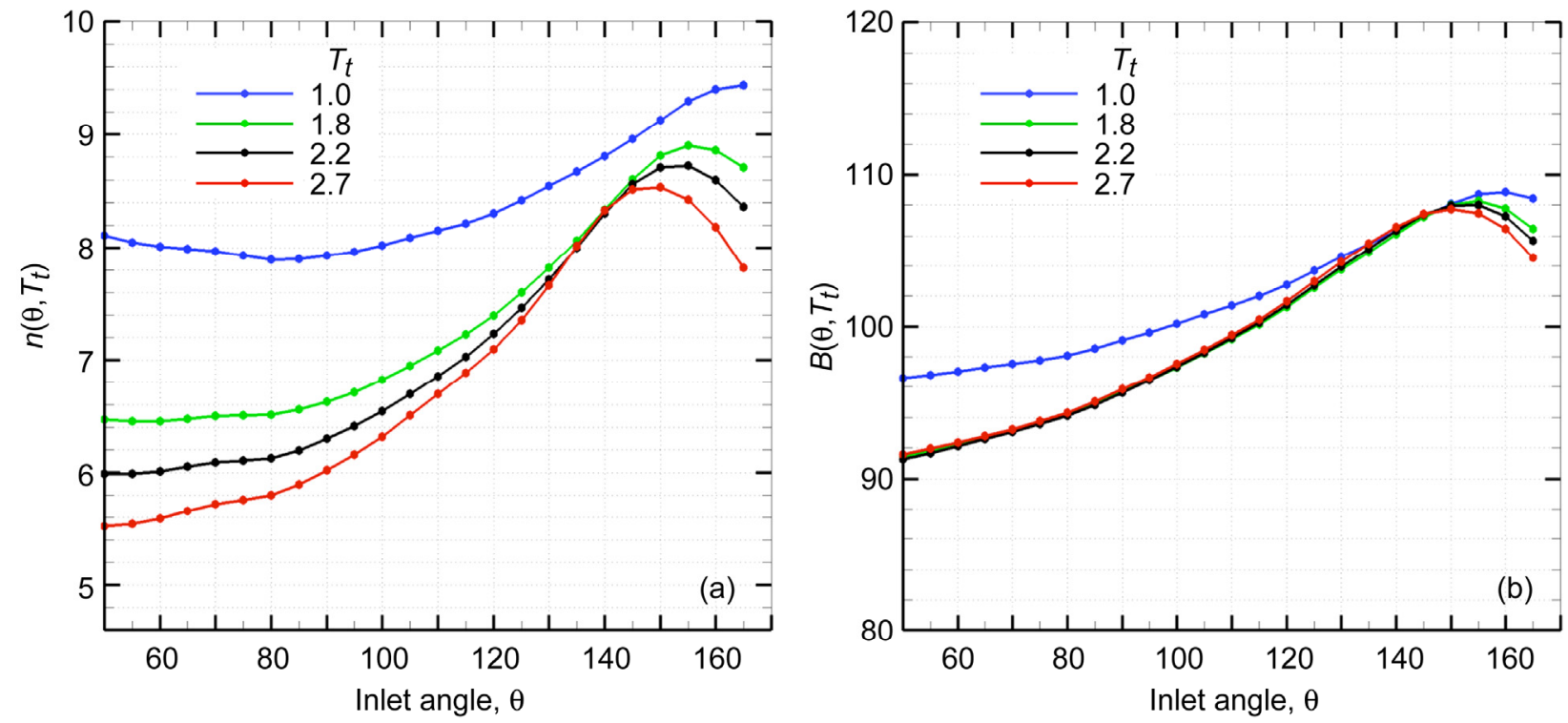

Figure 3.1.-Velocity power factor $n$ and the intercept parameter $B$ as a function of angle and stagnation temperature.

single static temperature when in reality it is affected by changes in the velocity profile. Experimentally, the plenum total temperature is a control parameter, while the static temperature at the jet exit is calculated using one-dimensional Bernoulli's equation for a compressible flow.

We now inspect the spectral collapse at selected angles, temperatures, and Mach numbers using a combination of different nozzles geometries.

The operation conditions for 9 jets at a constant stagnation temperature ratio of 1.0 are shown in Table 3.1. The first seven readings are due to a convergent nozzle smc000 (see Table 1.1 for nozzle geometry), with two readings 1616 and 1618 at underexpanded conditions. Reading 1636 is due to a CD nozzle operating at its design condition, i.e., $M_{d}=1.50, N P R_{d}=3.671$. The last reading (1605) is a convergent nozzle smc021, however the nozzle lip is modified with fine notches in order to minimize the screech-related noise at supersonic conditions.

TABLE 3.1.-SHJAR READINGS AT PLENUM TEMPERATURE RATIO 1.0
\begin{tabular}{|c|c|c|c|c|c|c|c|l|}
\hline Rdg & Nozzle & $T_{s}$ & $T_{t}$ & $U_{j} / c_{\infty}$ & $M$ & NPR & $M_{j}$ & $A_{j} / A_{e}$ \\
\hline 1610 & smc000 & 0.97 & 1.0 & 0.40 & 0.40 & 1.117 & 0.40 & 1.0 \\
1611 & & 0.96 & 1.0 & 0.49 & 0.50 & 1.186 & 0.50 & 1.0 \\
1612 & & 0.91 & 1.0 & 0.67 & 0.70 & 1.387 & 0.70 & 1.0 \\
1613 & & 0.86 & 1.0 & 0.83 & 0.90 & 1.692 & 0.90 & 1.0 \\
1614 & & 0.83 & 1.0 & 0.91 & 1.00 & 1.893 & 1.00 & 1.0 \\
1616 & & 0.76 & 1.0 & 1.08 & 1.00 & 2.556 & 1.24 & 1.043 \\
1618 & & 0.70 & 1.0 & 1.23 & 1.00 & 3.514 & 1.47 & 1.156 \\
1636 & smc016 & 0.69 & 1.0 & 1.24 & 1.50 & 3.671 & 1.50 & 1.0 \\
1605 & smc021 & 0.80 & 1.0 & 1.04 & 1.00 & 2.328 & 1.17 & 1.02 \\
\hline
\end{tabular}

Figure 3.2 shows the $90^{\circ}$ scaled power spectral density for all seven convergent nozzles following Equation 2.4. With the exception of the underexpanded cases, all spectra collapse at $n=7.93$ (see Fig. 3.1 for power factors) and within the uncertainty of the regression parameters. The two underexpanded jets at readings 1616 and 1618 contain shock-associated noise as well as intense screech. The screech tones appear as spikes in the spectra, and if one succeeds in eliminating such tones, then the jet mixing-noise is expected to dominate the spectra at low frequency even in the presence of the shock-associated noise. This is illustrated in Figure 3.2(b) with convergent nozzle smc021 at reading 1605, as well as Mach 1.50 CD nozzle at reading 1636. The lack of collapse of underexpanded spectral data to the level of 

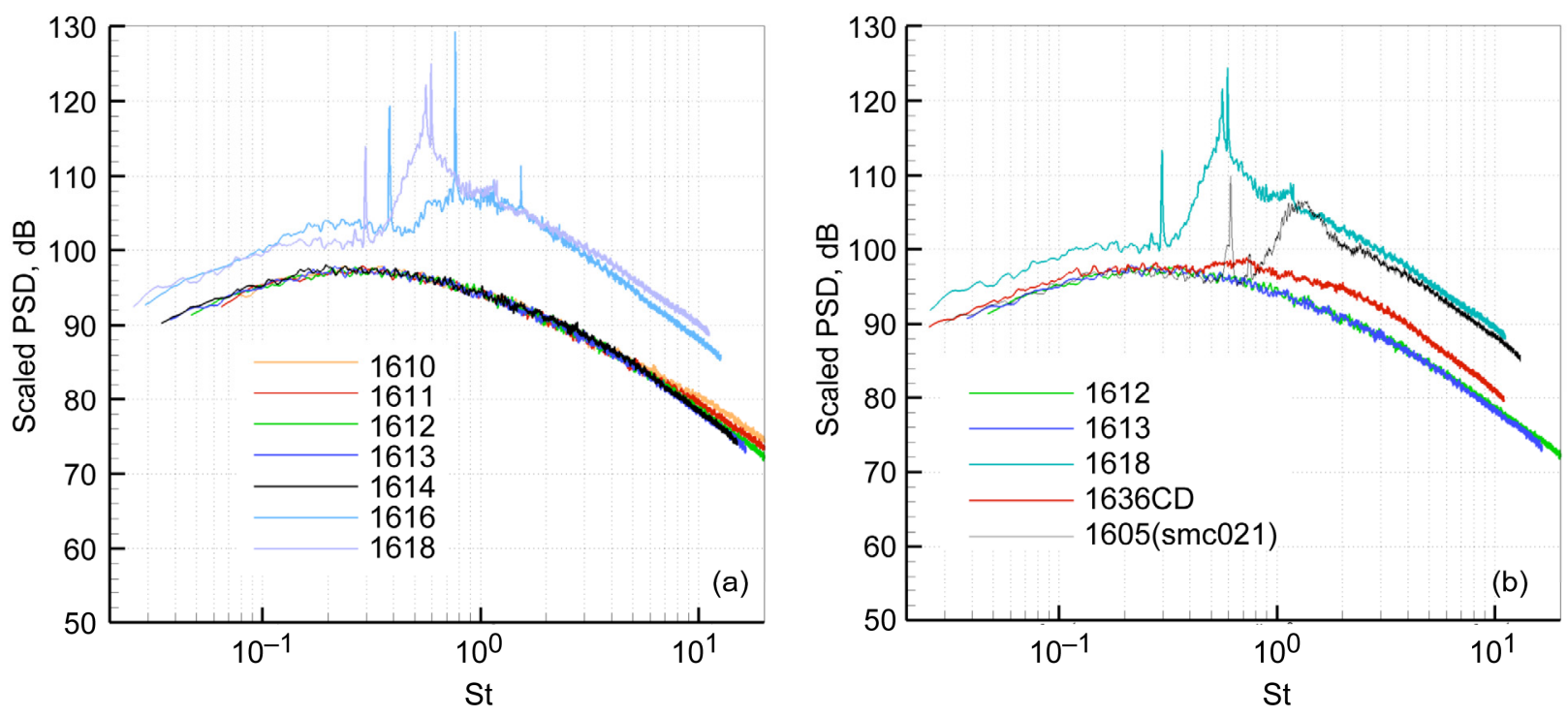

Figure 3.2.-Application of velocity power law at conditions of Table $3.1\left(T_{t}=1.0, \theta=90^{\circ}, n=7.93\right)$.
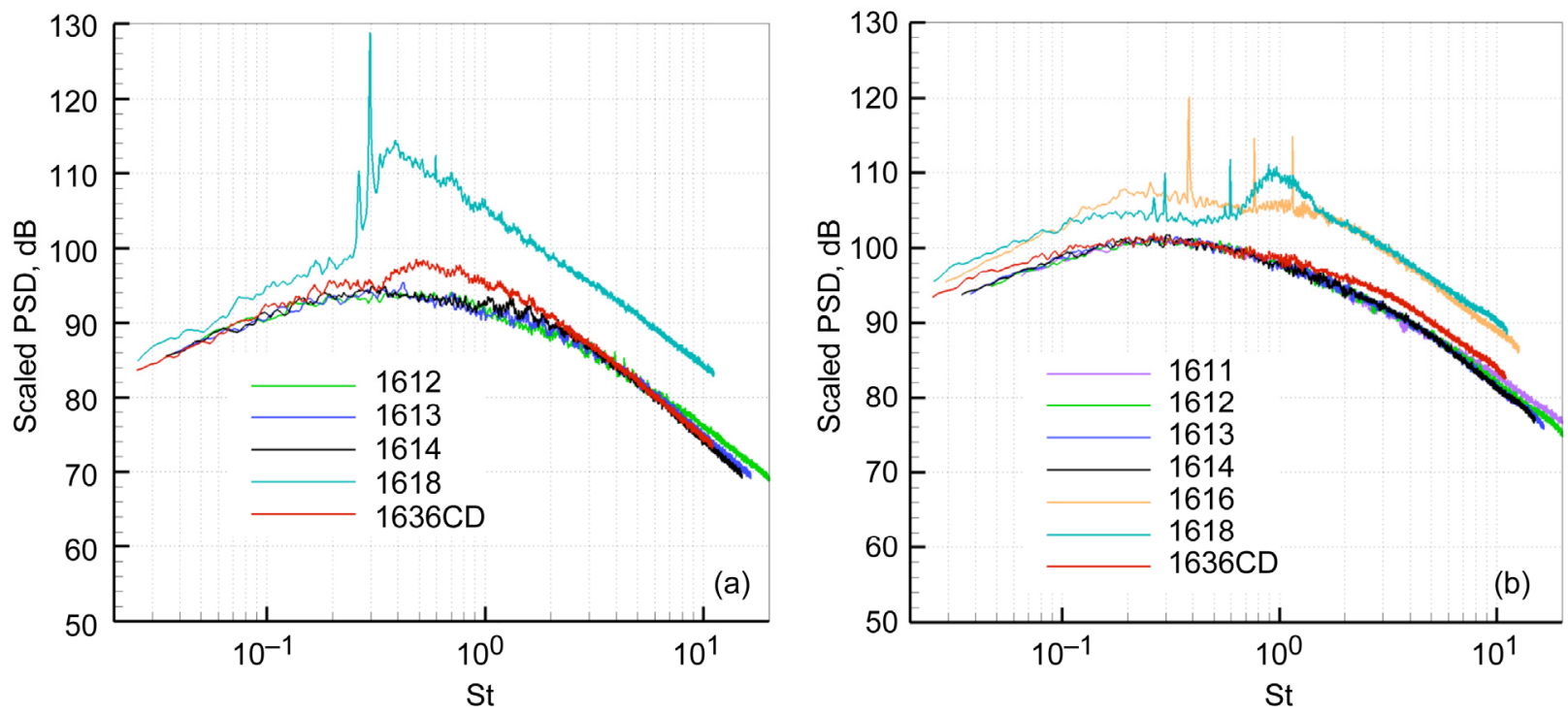

Figure 3.3.-Application of velocity power law at conditions of Table 3.1. (a) $T_{t}=1.0, \theta=50^{\circ}, n=8.11$. (b) $T_{t}=1.0$, $\theta=120^{\circ}, n=8.30$.

a fully expanded jet at low frequency, as seen in jet reading 1618, is attributed to an amplification of broadband jet noise due to screech. An amplification of $\sim 4.0 \mathrm{~dB}$ is noted in this case.

Experimental measurements of the turbulent kinetic energy in jets with and without screech show an increase in turbulence level with screech. Recent PIV measurements of Bridges et al. (Ref. 19) indicate a direct correspondence between broadband amplification noise and the additional turbulence measured in the presence of screech. Shear-layer excitation at a correct frequency often explains the reason for differences in noise measurements between different rigs. Jet noise prediction models that use a RANS input are unable to capture this amplification due to the inability of a time-averaged calculation to account for tone excitations. Such amplifications need to be removed from data prior to validation of predictions.

The scaled PSD is additionally examined at 50 and $120^{\circ}$ in Figure 3.3 using the appropriate velocity power factor $n(\theta, T)$. As the observer progressively moves towards aft angles, the BBSN noise weakens gradually, however, amplification effects may remain equally strong at all angles. 


\subsection{Collapse of Spectral Data at Small Aft Angles}

Two fundamental assumptions are buried in the spectral power law (Eq. 2.4). In the first place, it is implied that the basic shape of the spectrum at any angle $\theta$, described by the first term on the right, is invariant with respect to jet velocity and temperature. Second, since the spectral density is expressed as a function of the jet Strouhal frequency, spectra are assumed to peak at the same Strouhal number. When any of these assumptions are violated, data will collapse poorly, and other measures are necessary to fix that.

Figure 3.4(a) illustrates an attempt to collapse the subsonic noise data at $150^{\circ}$ (see Table 3.1). An inspection of the spectral data confirms that neither of the rules cited above hold at this angle. First, the spectra appear relatively wider at lower jet speeds, and display a broader peak. Higher speed jets, on the other hand, exhibit a well-defined peak. It is readily demonstrated that removing the lowest speed jet from the group would increase the value of the power factor $n$ from 9.13 to 9.32 . Removing the second lowest speed jet will still increase $n$ to 9.72. This is expected, as the area under the spectrum (on a Log basis) is highly dominated by the peak. When the peak covers a wider span, that particular jet would have an exaggerated effect on the power factor. The goodness factor described in the previous section remains small only when the general shape of the spectrum is preserved. Second, the peak Strouhal number is seen to vary between 0.18 and 0.35 .

Both problems are fixed once we increment the velocity power factor by 1.0, i.e., from 9.13 to 10.13 , and select the Helmholtz number $\left(f D / c_{\infty}\right)$ as the normalized frequency parameter as seen in Figure 3.4(b).

To see this more clearly, note that the power spectral density per Helmholtz number converts to that per Strouhal number according to

$$
10 \log \left(\overline{p^{2}} c_{\infty} / p_{r e f}^{2} D\right)=10 \log \left(\overline{p^{2}} U_{j} / p_{r e f}^{2} D\right)-10 \log \left(U_{j} / c_{\infty}\right)
$$

Therefore, the left hand side of Equation 2.4 may also be interpreted as the scaled power spectral density per Helmholtz number provided that $n$ is replaced with $(n+1)$ on the right hand side. For brevity, we choose "scaled $P S D$ " to represent either of the two meanings depending on the selection of the
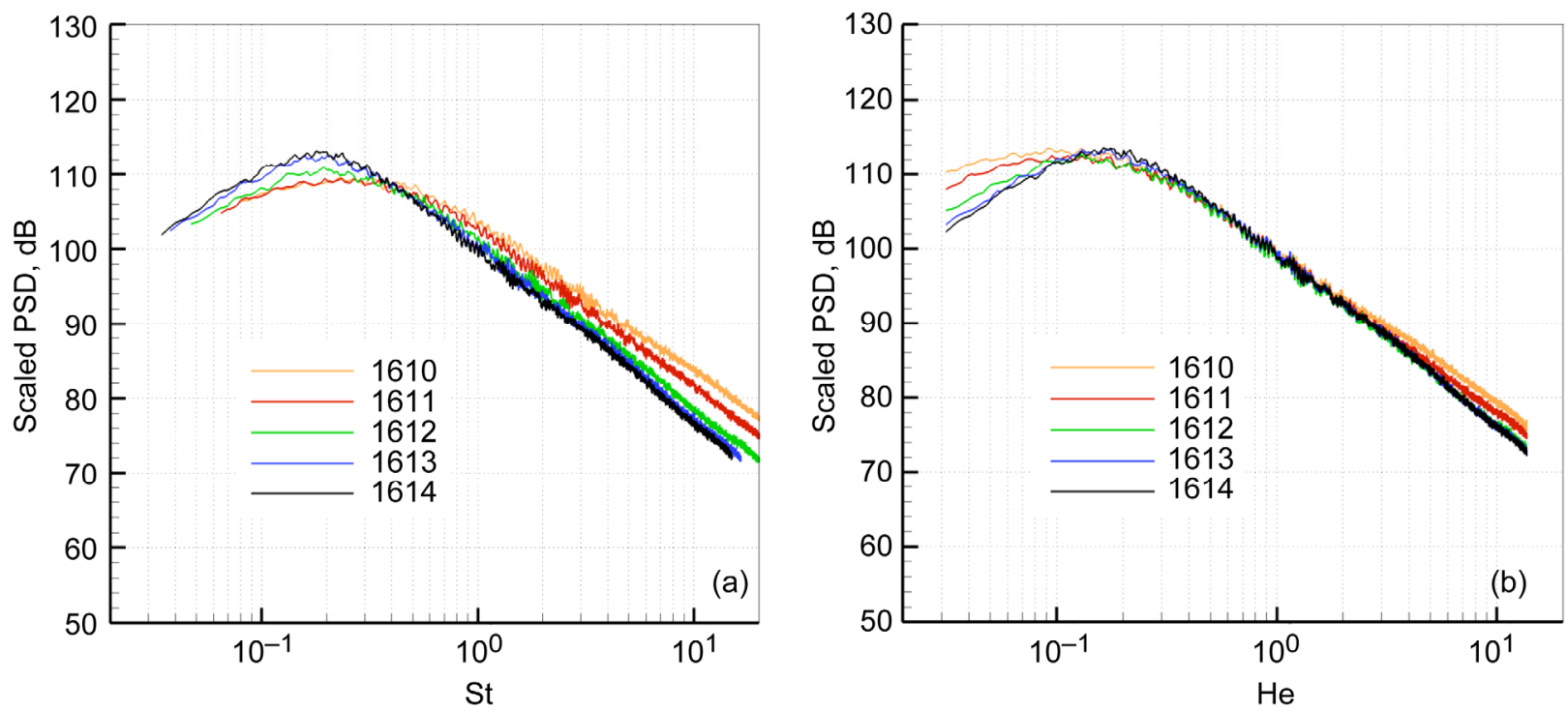

Figure 3.4.-Application of the power law at conditions of Table $3.1\left(T_{t}=1.0, \theta=150^{\circ}\right)$. (a) Scaled power spectral density per Strouhal no. $(n=9.13)$. (b) Scaled PSD per Helmholtz no. $(n=10.13)$. 

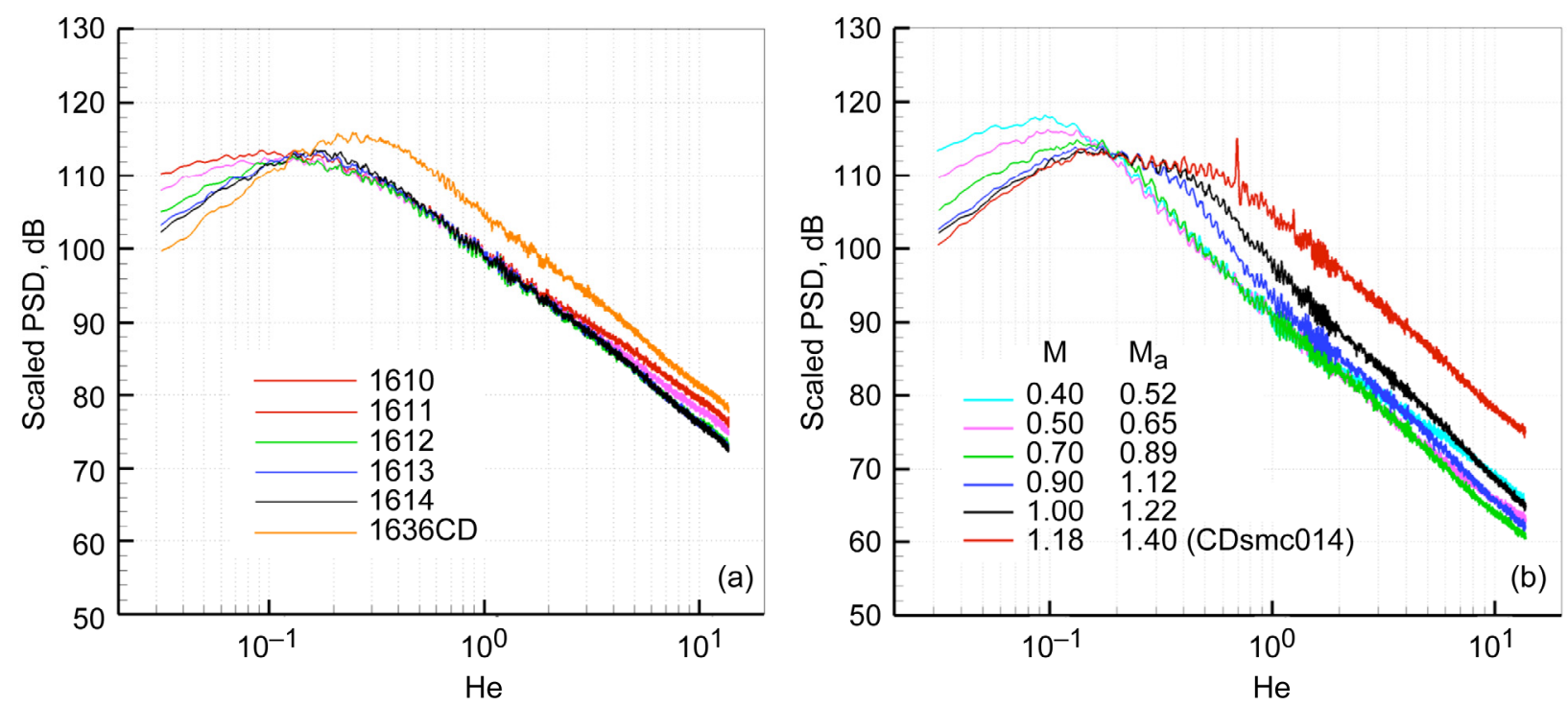

Figure 3.5.-Application of power law. (a) smc000 and smc016 nozzles at set points of Table $3.1\left(T_{t}=1.0, \theta=150^{\circ}\right.$, $n=9.13+1)$. (b) smc000 and Mach $1.18 \mathrm{smc014-CD} \mathrm{nozzles} \mathrm{at} \mathrm{indicated} \mathrm{Mach} \mathrm{numbers}\left(T_{t}=1.80, \theta=160^{\circ}\right.$, $n=8.90+1)$.

frequency parameter (and subsequent adjustment in parameter $n$ ). The difference in spectral shapes is now clearly seen as an increase in the low frequency noise in lower jet speeds, while the spectral amplitudes at higher frequencies collapse together for all subsonic conditions.

Failure of the velocity scaling of supersonic jet noise spectra at $150^{\circ}$ is seen in Figure 3.5 (a) when a shock-free CD nozzle (reading 1636-Table 3.1) is added to the subsonic jets. A better presentation of the supersonic spectra at small aft angles is shown in Figure $3.5(\mathrm{~b})$ at $160^{\circ}$ and at heated condition of $T_{t}=1.80$. The first 5 jets are due the convergent nozzle smc000, and the last jet is smc014-CD nozzle at its design point $M=1.18$. The scaled spectra show that the low frequency noise approaches a limit with increasing jet speed. As the acoustic Mach number exceeds 1.0, a broadening takes place at the spectral peak, and the high frequency roll off fails to collapse with a single velocity power factor. The high frequency noise shows a collapse as long as the acoustic Mach number remains subsonic. If the collapsed segment of the subsonic spectra is attributed to a particular generation mechanism, then it could arguably be scaled up to the velocity of a supersonic jet and be viewed as one component of noise at such speeds. The supersonic jet mixing noise at aft angles may, by itself, be considered as superposition of two incoherent components. More detailed study of the spectral features of jet noise at small aft angles is provided in Reference 5 .

\subsection{Shock Noise and Intensity Power Laws}

As pointed out previously, a typical jet noise spectrum could be a composite of three distinct components, i.e., jet mixing noise, shock-associated noise, and screech. Shock noise is due to the interaction of the jet turbulence with the shock cell structures under imperfectly expanded conditions, and dominates the spectra at mid to high frequency, mostly at forward and sideline angles (Refs. 20 to 23). Harper-Bourne and Fisher (Ref. 24) pioneered a formalism that estimates the shock noise component of supersonic jets. Screech noise, on the other hand, appears as isolated spikes at almost all angles when a jet is imperfectly expanded. Strong jet-related screech tones often excite the instabilities of the jet and enhance the broadband jet noise. The so-called amplification noise (AMN) may be identified when we scale up the jet mixing noise from a shock-free subsonic condition to the speed of a supersonic jet at the same temperature

$$
P S D_{2}=P S D_{1}+10 n(\theta, T) \log \left(U_{j 2} / U_{j 1}\right)+10 \log \left(A_{j 2} / A_{j 1}\right)
$$


Subscripts 1 and 2 refer to the lower-speed (i.e., datum) and higher-speed (i.e., destination) jets respectively. The lower speed jet is required to be shock-free (i.e., $A_{j 1} / A_{e}=1$ ). Let the spectral density associated with the mixing noise component in the higher speed jet be $P S D_{2}$. This component is evaluated by up scaling shock-free subsonic spectra at a similar angle and temperature as per velocity power laws. When amplification noise is minimal, $P S D_{2}$ should coincide with the total spectral density of jet2 at the initial segment of the spectrum (usually at $S t<0.10$ ), otherwise the difference is attributed to the amplification effect. To isolate the shock-associated noise in the higher speed jet, we subtract the mixing noise from the total noise. When amplification is not negligible, it may be accounted for two ways: (1) added to the mixing noise to calculate the matched-mixing noise or, (2) it could be included in the shock noise by subtracting the unmatched mixing noise from the total. Both methods are examined here.

A systematic approach to isolating the shock noise is presented in the following order:

(1) An under expanded convergent nozzle without broadband amplification effect AMN

(2) Under expanded convergent nozzle with intense screech and amplification AMN

(3) Convergent-divergent (CD) nozzles.

Within the first category a reduced-screech convergent nozzle at a nozzle pressure ratio $>1.89$ would be appropriate. An example is configuration smc021-1605 from Table 3.1 at NPR $=2.32$ (fully expanded Mach number of 1.17). To isolate the mixing noise component, velocity scaling is applied using any one of the subsonic jets at a similar stagnation temperature $T_{t}=1.0$ in Table 3.1. Figure 4.1(a) shows the total noise (blue), and the mixing noise (dark) at inlet angles of 50 to $120^{\circ}$. A nearly perfect match at the lowfrequency part of the spectra points to the absence of the amplification effect. Broadband shock associated noise BBSN is subsequently evaluated as

$$
10^{P S D(\text { shock }) / 10}=10^{P S D(\text { total }) / 10}-10^{P S D(\text { mixing }) / 10}
$$
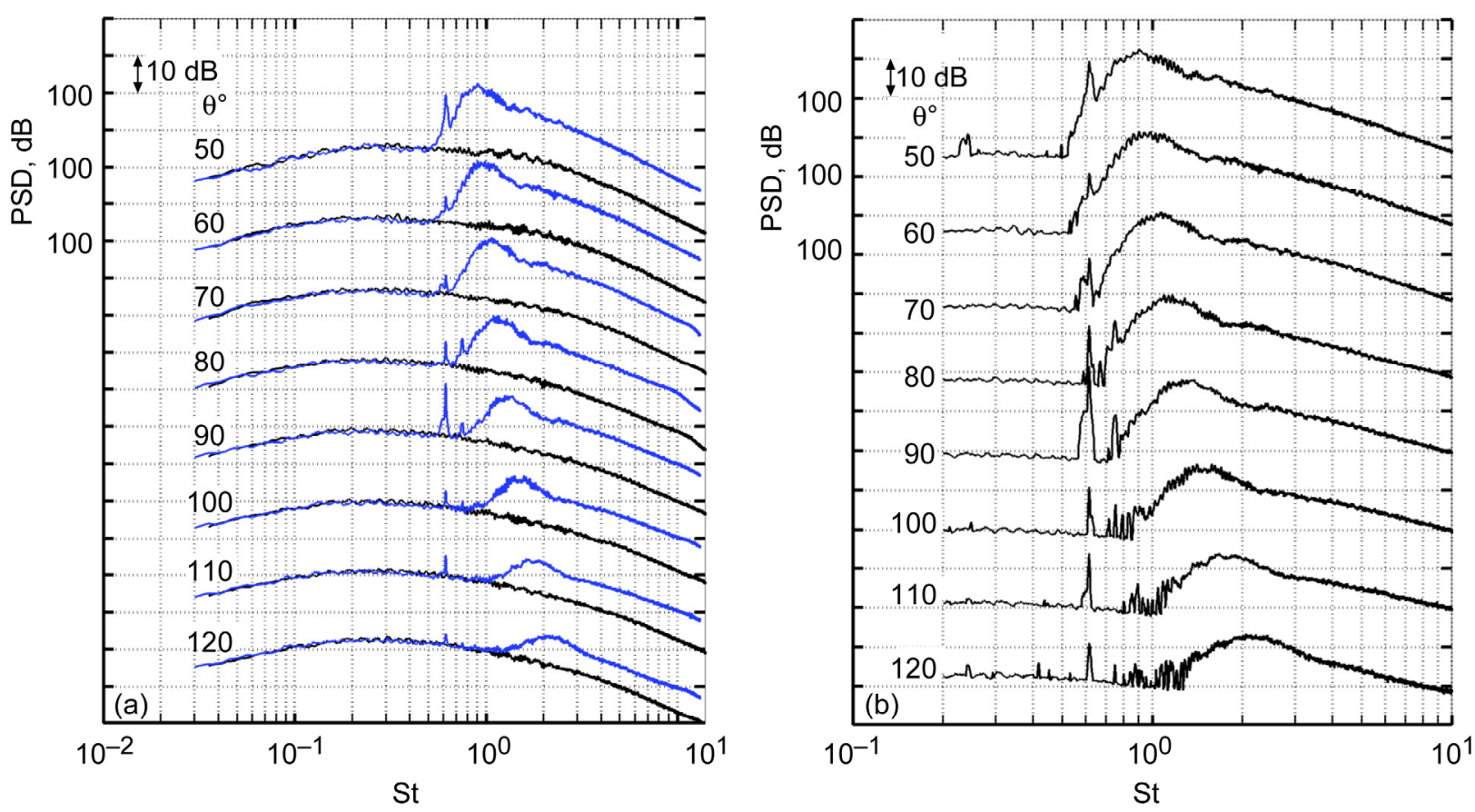

Figure 4.1.-Underexpanded convergent nozzle smc021 at reading 1605 (Table 3.1). (a) Total noise (blue); jet mixing noise (dark). (b) Shock-associated noise. 
Shown in Figure 4.1(b) is the BBSN, with peak values of $112.5 \mathrm{~dB}$ at $\left(S t=0.90, \theta=50^{\circ}\right)$, and $103.3 \mathrm{~dB}$ at $(S t=2.2$, $\theta=120^{\circ}$ ). The primary peak frequency of the BBSN is given as

$$
f_{p}=\frac{U_{c}}{L\left(1+M_{c} \cos \theta\right)}
$$

where $L=1.10 \sqrt{M_{j}^{2}-1} D$ according to HBF formulation (Ref. 24), and $L=\left(\pi / \sigma_{1}\right) \sqrt{M_{j}^{2}-1} D_{j}$ following Tam's formulations (Refs. 20 and 25) with $\sigma_{1}=2.40$, and $M_{\mathrm{c}}$ is the convection Mach number of the turbulent eddies $U_{c} / c_{\infty}$.

The shock-noise intensity, i.e., integrated spectrum in Figure 4.1(b), usually scales as $\beta^{m}$, where shock parameter $\beta=\sqrt{\left|M_{j}^{2}-M_{d}^{2}\right|}$ is a measure of deviation from the design point, and $m$ is the shock power factor. A nominal value for $m$ in chocked convergent nozzles is 4.0. Experimental measurements (Ref. 26) show that $m$ varies with both angle and temperature and approaches 4.0 in the very forward angle where BBSN is at its peak. Here we use the SHJAR measurements to examine a similar intensity law for the shock-associated noise. The linear regression method of Section 2 is applied as:

$$
\begin{array}{ll}
\hat{y}_{i}=O A S P L_{\text {shock }}(\theta, T), & i=1,2, \ldots, N \\
y_{i}=m(\theta, T) x_{i}+B(\theta, T) ; & x_{i}=10 \log \beta_{i}, \quad \beta_{i}=\sqrt{\left|M_{j, i}^{2}-M_{d}^{2}\right|}
\end{array}
$$

The intercept parameter $B$ is a measure of the BBSN intensity (dB) when $\beta=1$. In convergent nozzles $\left(M_{d}=1.0\right)$ this occurs at a nozzle pressure ratio of $\gamma^{\gamma /(\gamma-1)}$. As before, all intensity calculations are reported at $100 \mathrm{D}$ arc, and as lossless. In order to examine the intensity scaling for BBSN, two nozzles are considered here - a reduced screech convergent nozzle smc 021 at underexpanded conditions of Table 4.1, and the smc016 CD nozzle at both over- and under expanded conditions of Table 4.2.

TABLE 4.1-TEST CONDITIONS-CONVERGENT
NOZZLE SMC021 GROUPED AT CONSTANT
\begin{tabular}{|c|c|c|c|c|c|}
\hline Rdg & $T_{t}$ & $U_{j} / c_{\infty}$ & NPR & $M_{j}$ & $A_{j} / A_{e}$ \\
\hline 2079 & 1.0 & 0.95 & 2.00 & 1.048 & 1.00 \\
2080 & 1.0 & 1.04 & 2.36 & 1.178 & 1.02 \\
2081 & 1.0 & 1.18 & 3.15 & 1.392 & 1.11 \\
2082 & 1.0 & 1.24 & 3.64 & 1.493 & 1.17 \\
2083 & 1.0 & 1.34 & 4.65 & 1.659 & 1.30 \\
2085 & 1.0 & 1.40 & 5.70 & 1.795 & 1.43 \\
\hline 2088 & 1.80 & 1.26 & 2.00 & 1.049 & 1.00 \\
2089 & 1.80 & 1.38 & 2.35 & 1.181 & 1.02 \\
2090 & 1.80 & 1.57 & 3.15 & 1.391 & 1.11 \\
2091 & 1.80 & 1.65 & 3.63 & 1.492 & 1.17 \\
2092 & 1.80 & 1.77 & 4.64 & 1.659 & 1.30 \\
2093 & 1.80 & 1.85 & 5.69 & 1.791 & 1.43 \\
\hline 2100 & 2.20 & 1.39 & 2.00 & 1.045 & 1.00 \\
2098 & 2.20 & 1.53 & 2.35 & 1.180 & 1.02 \\
2097 & 2.20 & 1.73 & 3.14 & 1.390 & 1.11 \\
2096 & 2.20 & 1.82 & 3.62 & 1.493 & 1.17 \\
2095 & 2.20 & 1.96 & 4.64 & 1.659 & 1.30 \\
2094 & 2.20 & 2.05 & 5.67 & 1.793 & 1.43 \\
\hline 2102 & 2.70 & 1.54 & 1.99 & 1.048 & 1.00 \\
2103 & 2.70 & 1.69 & 2.33 & 1.174 & 1.02 \\
2104 & 2.70 & 1.92 & 3.12 & 1.390 & 1.11 \\
2105 & 2.70 & 2.02 & 3.60 & 1.489 & 1.17 \\
2106 & 2.70 & 2.17 & 4.63 & 1.660 & 1.30 \\
2107 & 2.70 & 2.27 & 5.65 & 1.789 & 1.43 \\
\hline
\end{tabular}


TABLE 4.2-TEST CONDITIONS-CD NOZZLE

$\operatorname{SMC016}\left(M_{D}=1.50\right)$ AT STAGNATION

TEMPERATURE RATIO $T_{t}=1.0$

\begin{tabular}{|l|l|l|l|l|}
\hline Rdg & $U_{j} / c_{\infty}$ & NPR & $M_{j}$ & $A_{j} / A_{e}$ \\
\hline 1636 & 1.246 & 3.669 & 1.500 & 1.0 \\
1637 & 1.250 & 3.701 & 1.505 & 1.002 \\
1638 & 1.254 & 3.739 & 1.512 & 1.006 \\
1639 & 1.266 & 3.851 & 1.532 & 1.016 \\
1640 & 1.285 & 4.046 & 1.566 & 1.033 \\
1641 & 1.309 & 4.323 & 1.611 & 1.058 \\
1642 & 1.339 & 4.704 & 1.667 & 1.092 \\
1643 & 1.372 & 5.207 & 1.735 & 1.137 \\
1644 & 1.418 & 5.995 & 1.827 & 1.206 \\
\hline 1628 & 0.947 & 2.003 & 1.047 & 0.889 \\
1629 & 1.051 & 2.405 & 1.193 & 0.901 \\
1630 & 1.119 & 2.749 & 1.294 & 0.923 \\
1631 & 1.174 & 3.098 & 1.381 & 0.950 \\
1632 & 1.212 & 3.383 & 1.443 & 0.974 \\
1633 & 1.226 & 3.498 & 1.466 & 0.984 \\
1634 & 1.238 & 3.602 & 1.486 & 0.993 \\
1635 & 1.244 & 3.654 & 1.496 & 0.998 \\
\hline
\end{tabular}
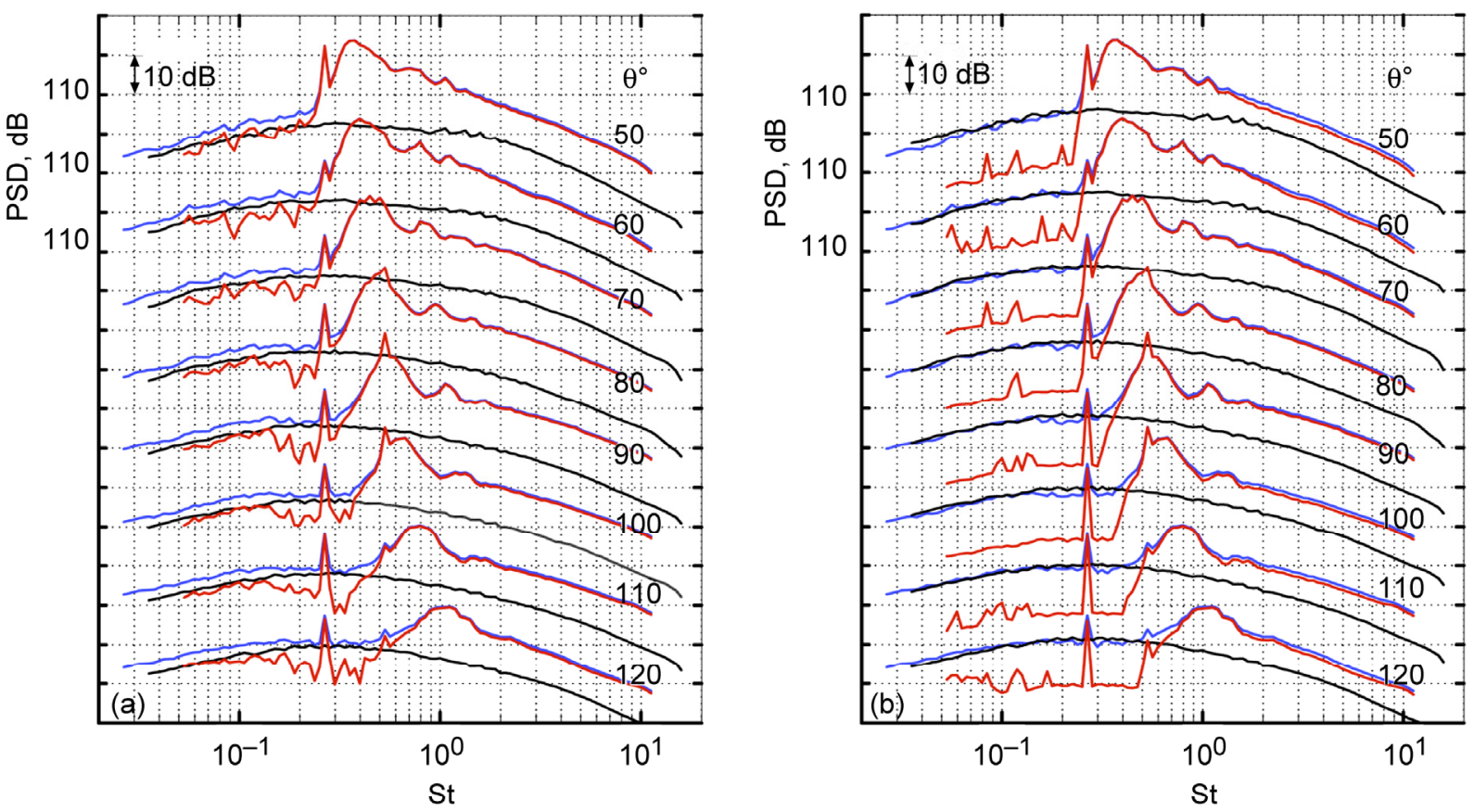

Figure 4.2.-Decomposition of total noise into mixing and shock noise components in Mach 1.49 convergent nozzle smc021 at NPR = 3.64 (reading 2082, Table 4.1). Total noise (blue); jet mixing noise (dark); shock-associated noise (red). (a) Mixing noise excludes amplification. (b) Mixing noise includes amplification.

The convergent nozzle is examined first. Figure 4.2(a) illustrates the application of the velocity power law to a typical jet condition (i.e., reading 2082 - Table 4.1) whereby the total noise is decomposed into its two components. Unlike the previous example shown in Figure 4.1, the mixing noise and the total noise fail to collapse together at the early stages of the spectra. The difference $(\sim 2.0$ to $3.0 \mathrm{~dB})$ is due to the amplification noise (AMN). Shown in Figure 4.2(b) are the matched-mixing noise and the subsequent BBSN. Note that the shock-associated noise is slightly different depending on how the amplification is book kept. 

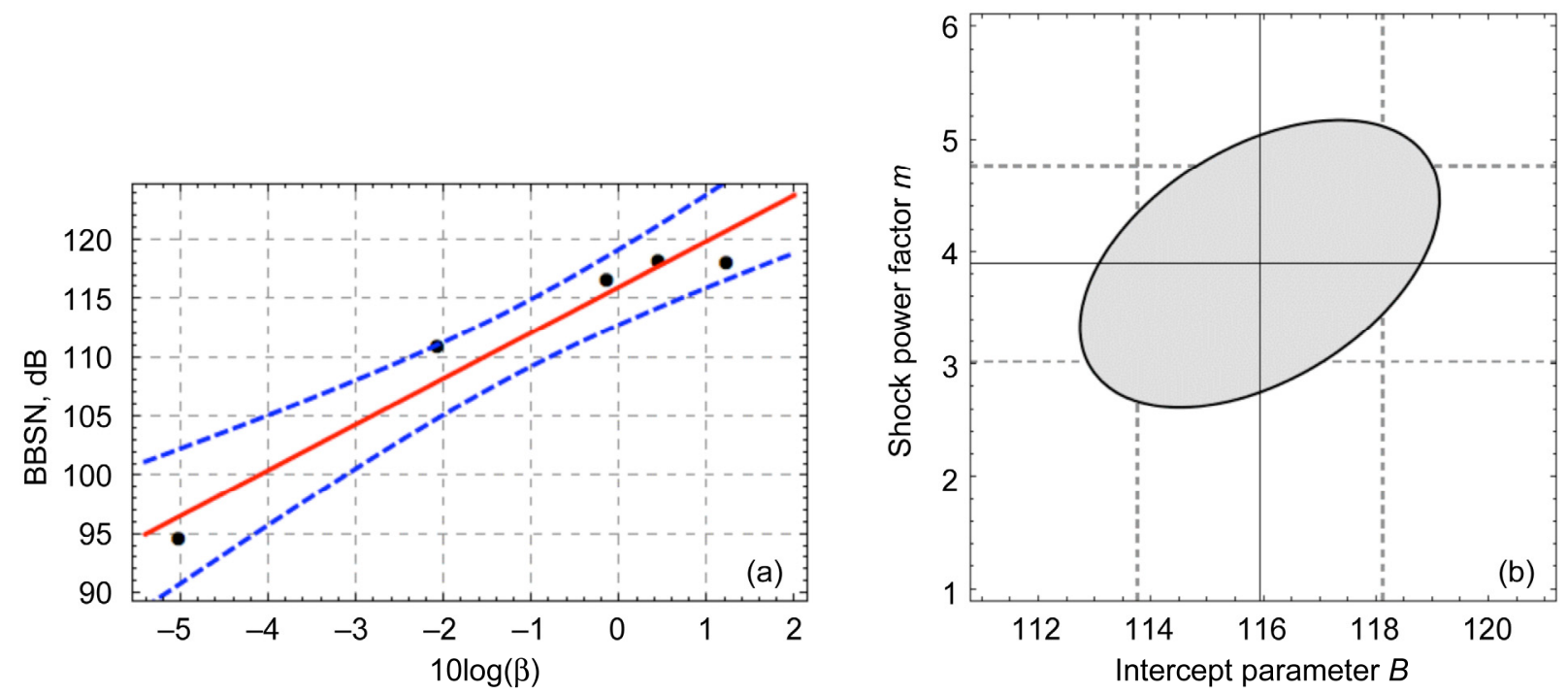

Figure 4.3-(a) BBSN versus shock parameter $\beta$ in the convergent nozzle smc021 at $T_{t}=1.0, \theta=50^{\circ}$ : data (symbols); least squares fitted line (red); and the $80 \%$ confidence band (dashed lines). (b) $80 \%$ Joint confidence margin (shaded region) and marginal inference intervals (dashed lines) for shock power factor $m$ and intercept $B$.
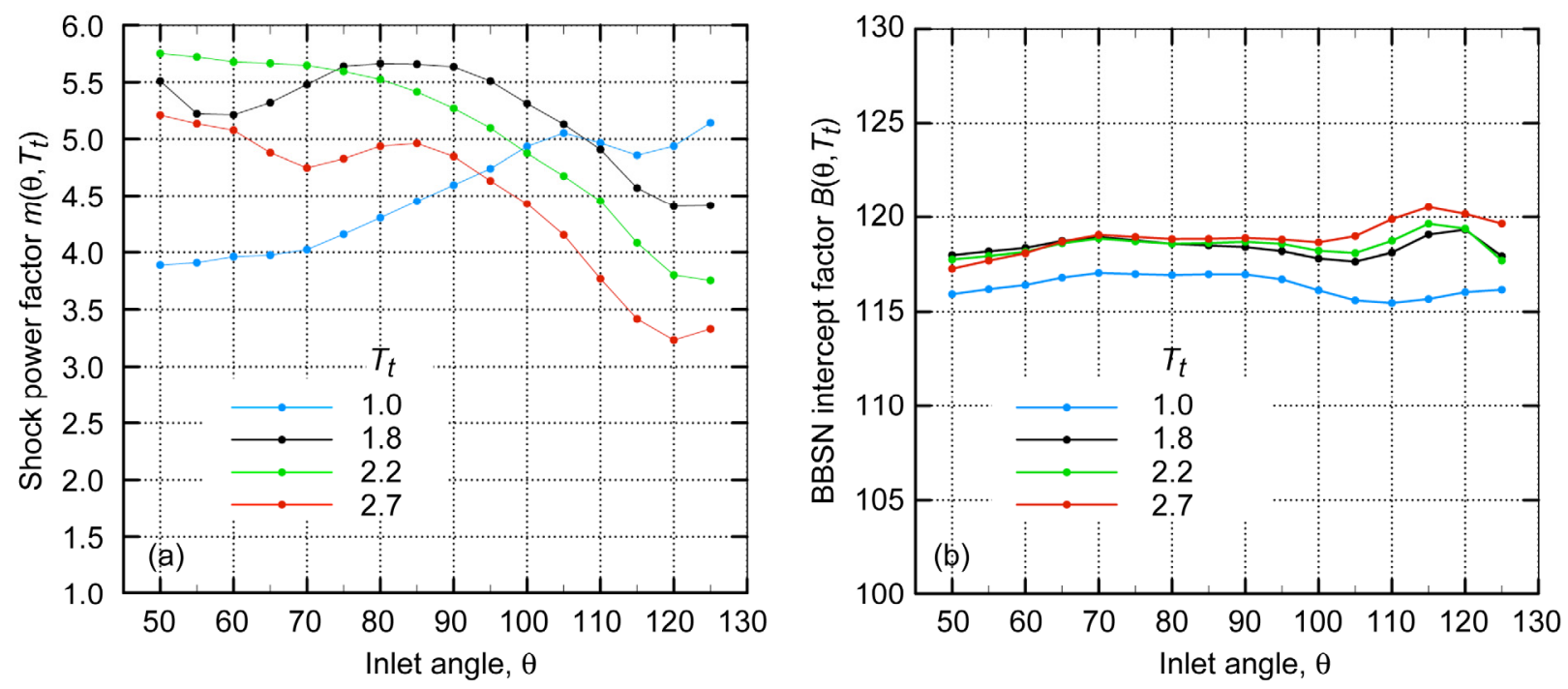

Figure 4.4.-Shock factors versus angle and temperature in an underexpanded convergent nozzle smc021 when amplification is included in mixing noise. (a) Shock power factor $m\left(\theta, T_{t}\right)$. (b) Intercept parameter $B\left(\theta, T_{t}\right)$.

Application of the least squares method to the BBSN at $\theta=50^{\circ}$ and $T_{t}=1.0$ at moderately underexpanded conditions is shown in Figure 4.3. Set point 2085 at NPR $=5.70$ has been removed from least squared fit in order to reduce the data scatter and improve the confidence margins. In this figure, the AMN noise component has been added to the mixing noise similar to Figure 4.2(b). At 80 percent confidence margin, the interpolation parameters cover inference intervals of $m=3.89 \pm 0.90$, $B=115.93 \pm 2.15$.

Figure 4.4 shows the two parameters $m\left(\theta, T_{t}\right)$ and $B\left(\theta, T_{t}\right)$ for the convergent nozzle at four temperatures. The unheated jets show a distinctly different set of parameters, and at a constant $M_{j}$ radiate less BBSN at forward angles where shock noise its relatively strong. Figure 4.5 shows the shock 

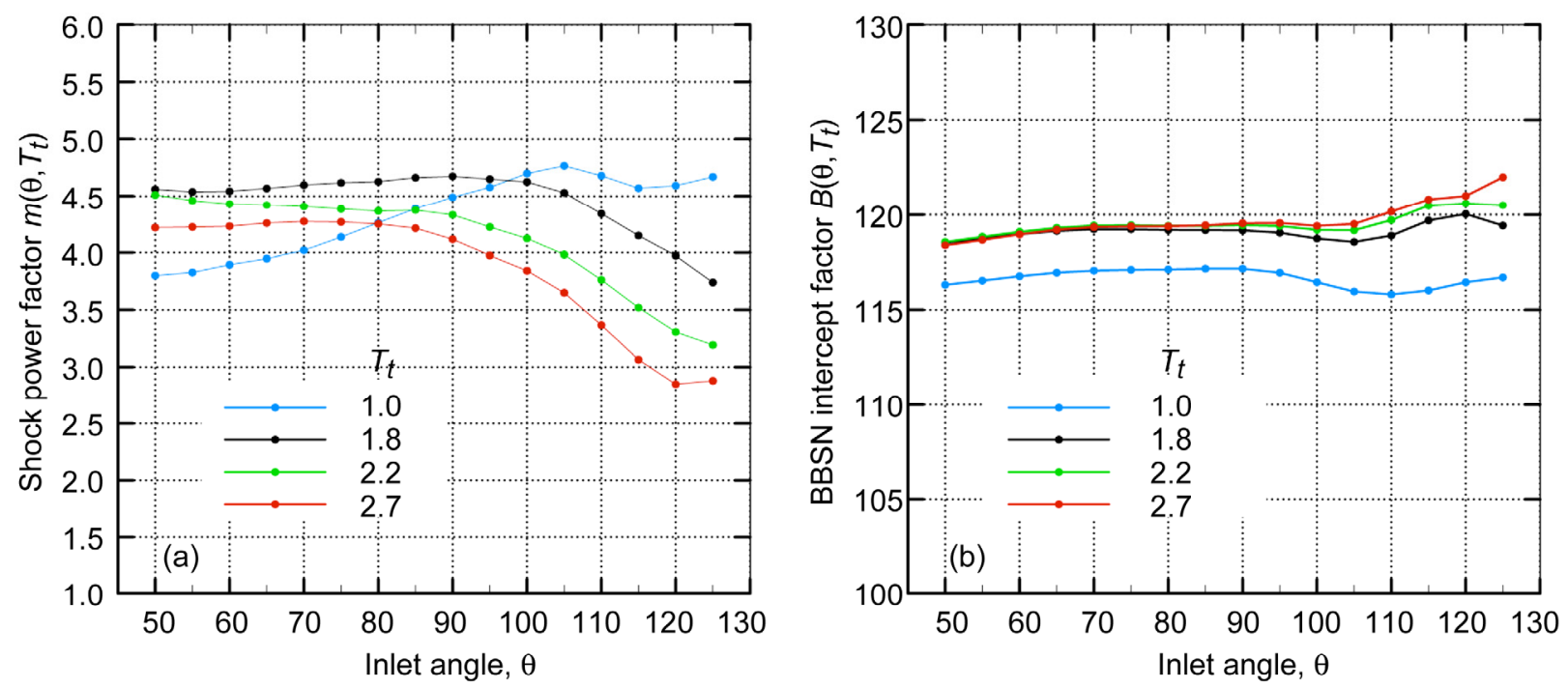

Figure 4.5.- Shock factors versus angle and temperature in an underexpanded convergent nozzle smc021 when amplification is included in shock noise. (a) Shock power factor $m\left(\theta, T_{t}\right)$. (b) Intercept parameter $B\left(\theta, T_{t}\right)$.
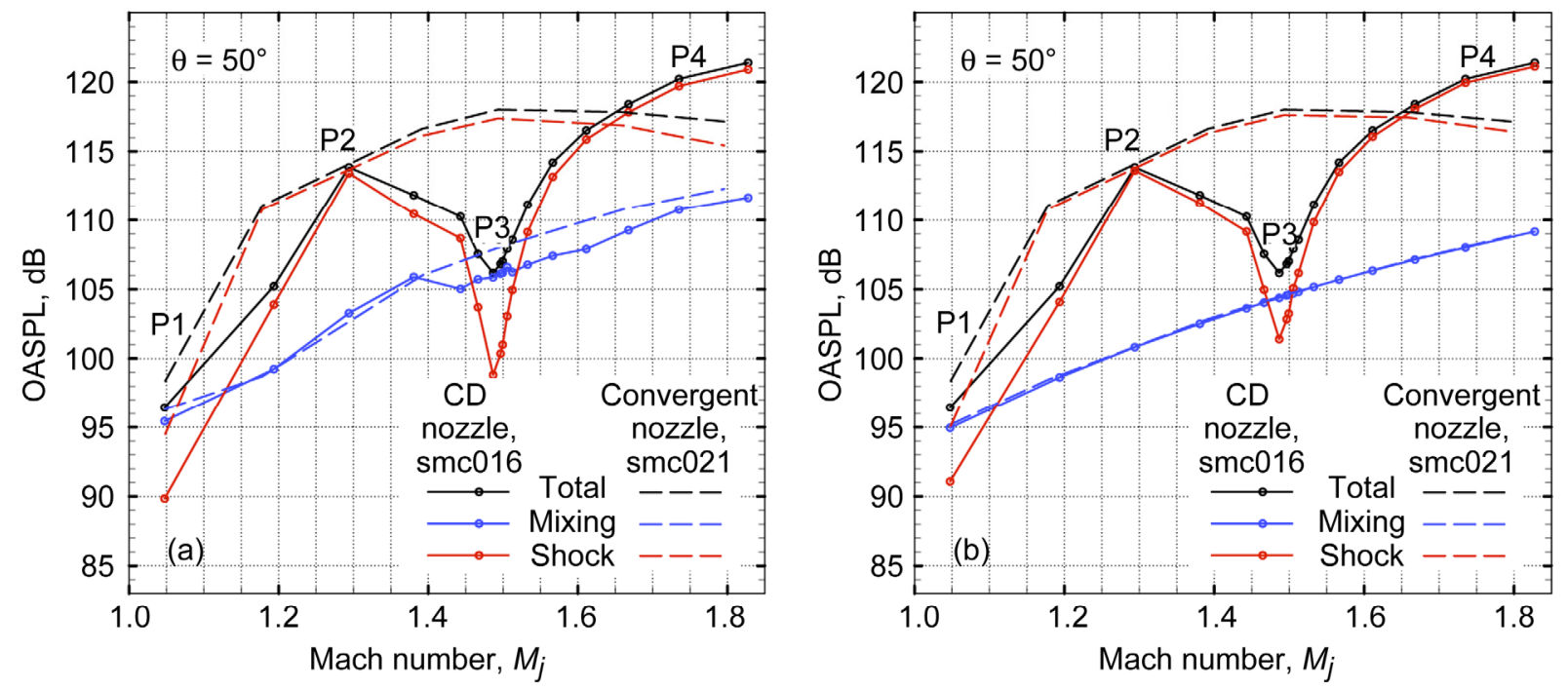

Figure 4.6.-Noise components in convergent nozzle smc021 and CD nozzle smc016 versus fully expanded Mach number $M_{j}$ at $50^{\circ}$ and at $T_{t}=1.0$. (a) Amplification is added to mixing noise. (b) Amplification is included in BBSN noise.

parameters for the same nozzle conditions if amplification noise were considered as part of the BBSN and component decomposition were carried out according to Figure 4.2(a). As before, the heated jets display distinctly different characteristics with their amplitude parameter $B$ clustered together for most of the angle range. The marginal inference intervals of parameters $m$ and $B$ (not shown here) are quite comparable irrespective of the decomposition method.

Next, we examine the shock parameters in the Mach 1.50 CD nozzle (smc016). Test conditions consist of unheated set points only, as listed in Table 4.2, including both under and over expanded conditions. As before, when screech-related amplification is present, noise elements are distinguished using two methods of component splitting. Sample result at $\theta=50^{\circ}$ is shown in Figure 4.6, where amplification is added to the mixing noise (part a), or is considered as part of the shock noise (Part b). The same figure also displays noise components in the convergent nozzle smc021 following a similar 

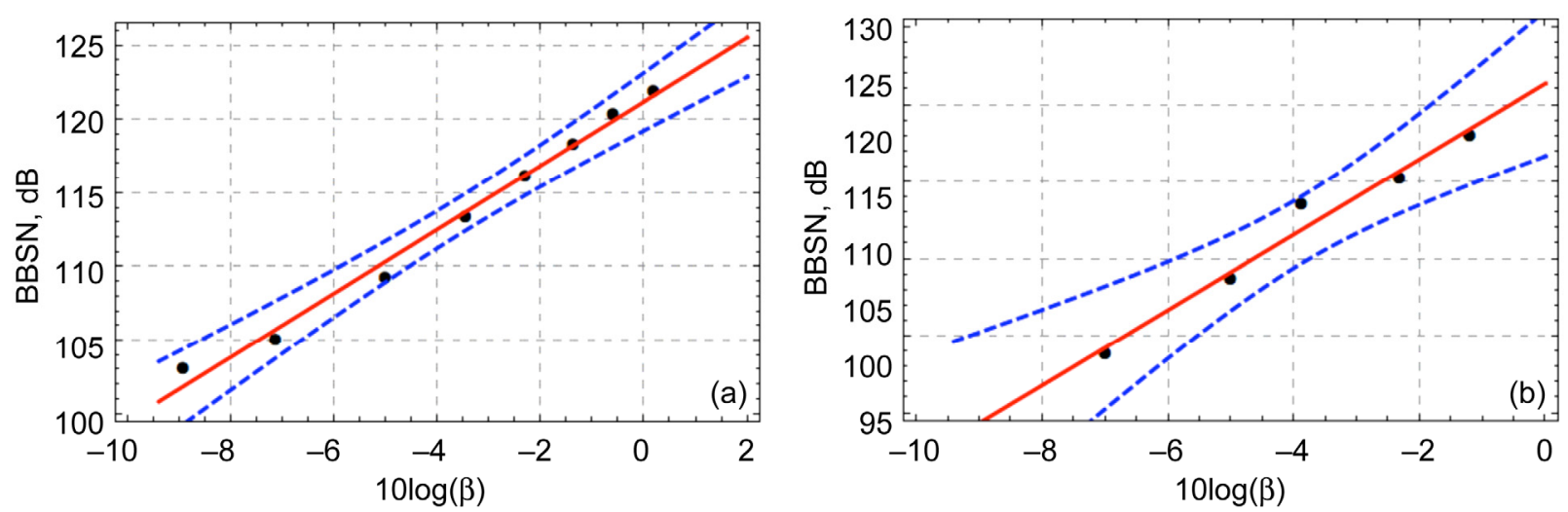

Figure 4.7-BBSN versus shock parameter $\beta$ in the CD nozzle smc016 at $M_{d}=1.50$ and $T_{t}=1.0, \theta=50^{\circ}:$ data (symbols); least squares fitted line (red); $95 \%$ confidence band (dashed lines). (a) Underexpanded regime.

(b) Overexpanded regime.
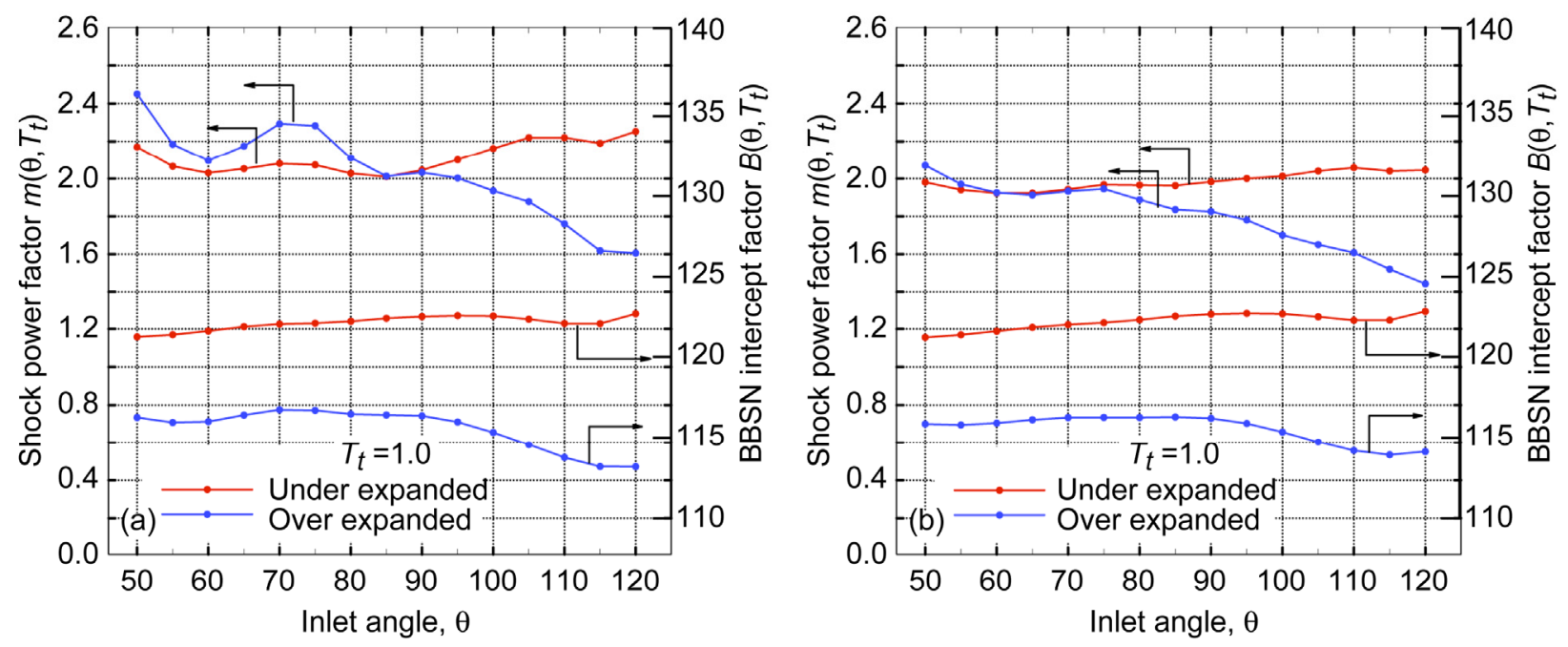

Figure 4.8.-Shock noise power factors $m\left(\theta, T_{t}\right)$ and intercept factor $B\left(\theta, T_{t}\right)$ in the CD nozzle smc016.

(a) Amplification is added to mixing noise. (b) Amplification is included in the BBSN noise.

decomposition. Point P3 displays the design conditions for the CD nozzle. Away from the design point, BBSN intensifies in both under expanded (P3-P4) and over expanded (P3-P2) regimes of the CD nozzle.

A linear interpolation of the BBSN is relatively successful only when we confine the least squares method to the moderately imperfectly expanded conditions, subsequently interval points (P2-P1) are excluded from the following linear interpolation. In highly overexpanded jets, a normal shock occurs within the nozzle and flow decelerates through the remaining diverging section and exhausts as a subsonic jet. Experimental results of (Ref. 27) indicate that an additional broadband noise component could also be generated in the low Mach number range of the overexpanded regime, depending on the expansion angle of the divergent section.

Figure 4.7 shows sample interpolations at $\theta=50^{\circ}$ with readings (1637-1644) and (1630-1634) from Table 4.2, and following component splitting of Figure 4.6(a). The joint confidence margins are $m=2.17 \pm 0.32, B=121.17 \pm 1.50$ in the underexpanded regime, and $m=2.45 \pm 0.77, B=116.31 \pm 2.49$ in the overexpanded regimes, respectively.

Shown in Figure 4.8 are the BBSN intensity interpolation parameters $m\left(\theta, T_{t}\right)$ and $B\left(\theta, T_{t}\right)$ in the unheated $\mathrm{CD}$ nozzle using two different methods for bookkeeping of the amplification noise. The shock power factor $m$ is slightly different in the under and over expanded regimes, however within the 
uncertainty of the regression $m \sim 2.0$ in the forward angles, which is almost half of that for a convergent nozzle at a similar temperature (Figs. 4.4 and 4.5).

\subsection{Modified Shock Parameter}

Interpolation parameters $m\left(\theta, T_{t}\right)$ and $B\left(\theta, T_{t}\right)$ associated with the BBSN as evaluated in the previous section depend on the nozzle design point. For example, in the convergent nozzle with unheated jets, $m \cong 4$ and $B \cong 117.0 \mathrm{~dB}$ at forward angles (Figs. 4.4 and 4.5) - while in the CD nozzle $m \cong 2.0$ and $B \cong$ $116.0 \mathrm{~dB}$ or $121.0 \mathrm{~dB}$ depending on the overexpanded or underexpanded regimes, respectively (Fig. 4.8). It is practically more desirable to obtain a set of parameters that are independent of the nozzle design point or mode of operation in the CD nozzles. Subsequently, a modified shock intensity parameter $\beta_{m}$ is defined as

$$
\begin{array}{ll}
\beta_{m, i}=\left(\beta_{i} M_{d}^{3 / 2}\right)^{M_{d}^{-3 / 2}}, & \text { underexpanded } \\
\beta_{m, i}=\left(\beta_{i}\right)^{M_{d}^{-3 / 2}}, & \text { overexpanded }
\end{array}
$$

Only CD nozzles are affected by the new definition. As seen in Figure 4.9, there is a relative collapse of the intercept parameter $B$ between different modes of operation. In addition, parameter $B$ is also in agreement with the convergent nozzle at a similar temperature, and within the uncertainty of regression scheme. The new estimates for the shock power factor $m$ also exhibit less discrepancy relative to the convergent nozzle at aft angles. The gap in power factors at aft angles remains as before due to a steady reduction in $m$ with increasing angle $\theta$ in overexpanded jets. Also shown in Figure 4.10 are typical regression results using the new parameter $\beta_{m}$. The rescaled shock parameter affects the horizontal distribution of regression points as shown in Figures 4.10(a) and 4.7(a).
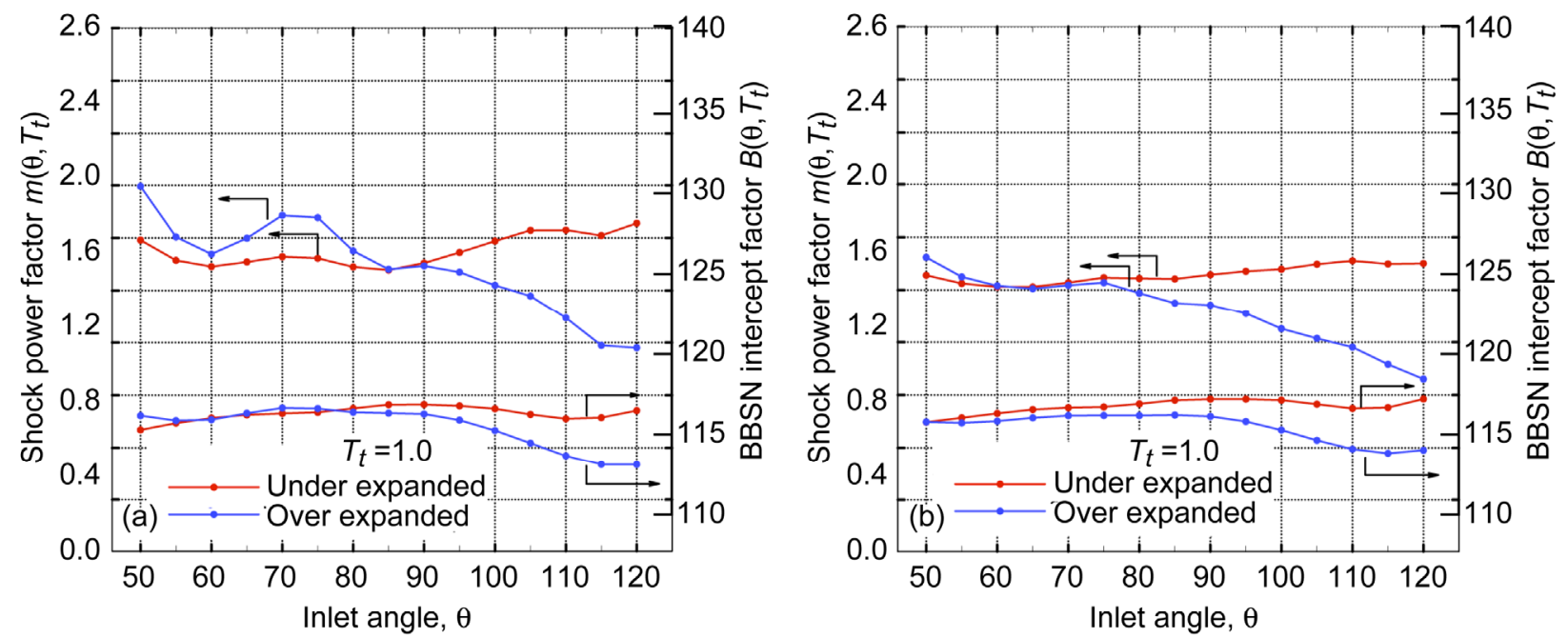

Figure 4.9.-Shock noise power factors $m\left(\theta, T_{t}\right)$ and intercept factor $B\left(\theta, T_{t}\right)$ in the CD nozzle smc016 with a modified shock parameter $\beta_{m}$ as defined in Equation 4.5. (a) Amplification is added to mixing noise. (b) Amplification is included in the BBSN noise. 

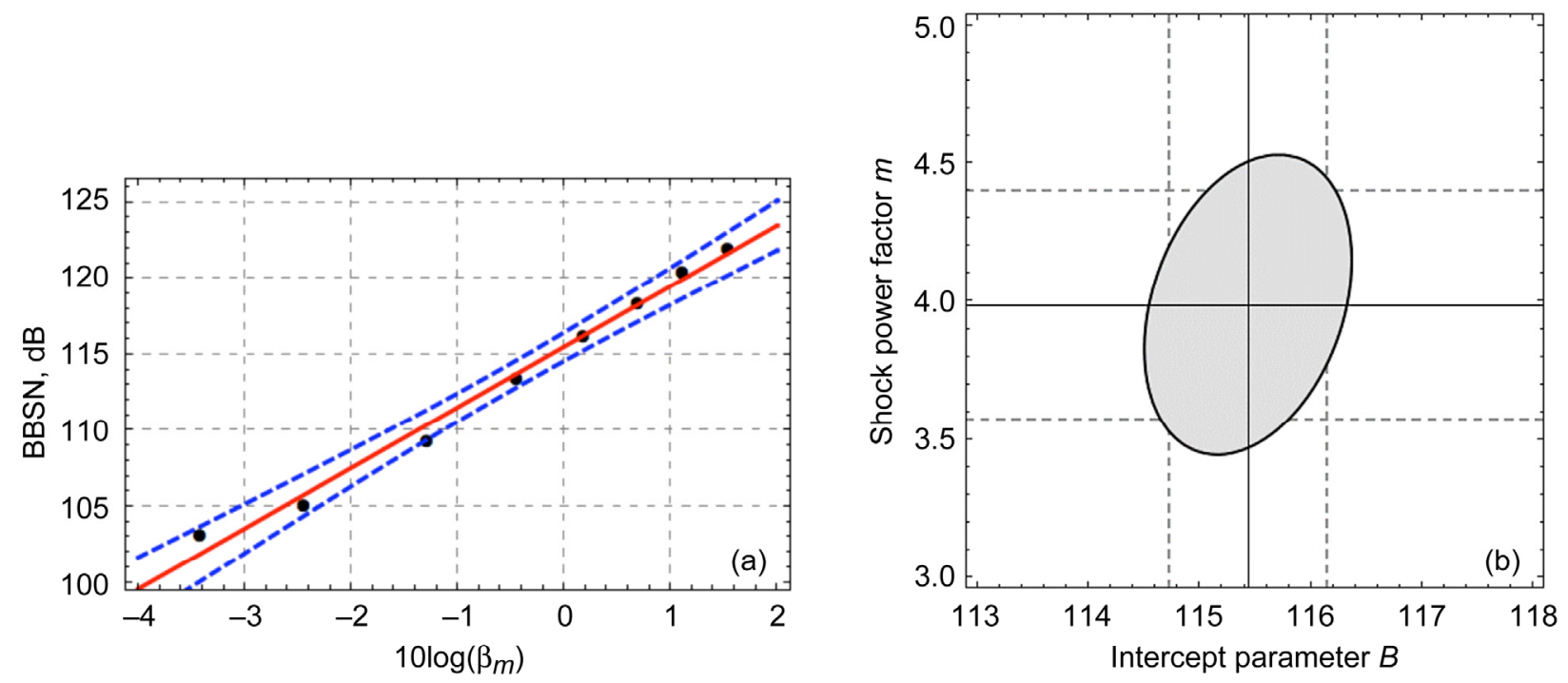

Figure 4.10-(a) BBSN versus modified shock parameter $\beta_{m}$ in the convergent nozzle smc016 at $T_{t}=1.0, \theta=50^{\circ}$ : data (symbols); least squares fitted line (red); and the $95 \%$ confidence band (dashed lines). (b) $95 \%$ Joint confidence margin (shaded region) and marginal inference intervals (dashed lines) for shock power factor $m$ and intercept $B$. (Amplification is added to the mixing noise).

\section{Summary}

An extensive database of jet noise has been analyzed, correlating power spectral density as a function of angle and temperature over a range of jet velocities in single stream jets. Velocity scaling of jet mixing noise was shown to be equally successful at constant static or stagnation temperatures. In general, two parameters are needed to achieve a successful scaling when jets are at different temperatures, although at higher temperatures, a single parameter $n$ will suffice at most angles as shown in Figure 3.1(b). Spectral collapse of jet noise data at small aft angles is less successful due to changes in the spectral shape with jet speed. A collapse of the high frequency roll off of amplitudes at aft angles is achieved with Helmholtz frequency only when the acoustic Mach number is subsonic.

Velocity scaling of the jet mixing noise helps identify other noise components, such as broadband amplification of jet noise in the presence of screech, and the broadband shock associated noise. Two different methods were discussed in bookkeeping of the amplification noise, and subsequent shock noise intensity parameters were evaluated for convergent and convergent-divergent nozzles using a linear regression method. Finally, a modified shock intensity parameter was introduced that allows the two regression parameters to be less dependent on the nozzle design point within the uncertainty margins of the interpolation method.

Scaling laws should help with jet noise data evaluation, component identification, and most importantly with the development of jet noise prediction tools.

\section{References}

1. Lighthill, M.J., "On Sound Generated Aerodynamically: 1. General Theory," Proceedings of the Royal Soc. (London), 211A, pp. 564-587, 1952.

2. Goldstein, M.E., Aeroacoustics, McGraw Hill, 1976.

3. Viswanathan, K., "Scaling Laws and a Method for Identifying Components of Jet Noise," AIAA Journal, 44(10), pp. 2272-2285, 2006.

4. Tam, C.K. W., "Dimensional Analysis of Jet-Noise Data," AIAA Journal, 44(3), pp. 512-522, 2006.

5. Khavaran, A., and Bridges, J., "SHJAR Jet Noise Data and Power Spectral Laws," NASA TM-2009215608, March, 2009. 
6. Bechert, D., and Pfizenmaier, E., "On the Amplification of Broadband Jet Noise by Pure Tone Excitation," J. Sound and Vibration, 43, pp. 581-587, 1975.

7. Ahuja, K.K., and Blankney, D.F., "Tone Excited Jets, Part IV: Acoustic Measurements," J. Sound and Vibration, 102(1), pp. 93-118, 1985.

8. Moore, C.J., “ The Role of Shear-Layer Instability Waves in Jet Exhaust Noise," J. Fluid Mechanics, 80, pp. 321-367, 1977.

9. Bridges, J. and Brown, C. A., "Validation of the Small Hot Jet Rig for Jet Noise Research", AIAA Paper 2005-2846, May, 2005.

10. Brown, C. A., and Bridges, J., "Small Hot Jet Acoustic Rig Validation," NASA/TM-2006-214234, 2006.

11. Bridges, J., and Wernet, M.P., "Measurements of the Aeroacoustic Sound Sources in Hot Jets," AIAA Paper 2003-3130, 2003.

12. Bridges, J., and Wernet, M.P., "Effect of Temperature on Jet Velocity Spectra," AIAA Paper 20073628, 2007.

13. Lush, P.A., "Measurements of Subsonic Jet Noise and Comparison with Theory," J. Fluid Mechanics, 46(3), pp. 477-500, 1971.

14. Hoch, R.G., Duponchel, J.P., Cockling, B.J., and Bryce, W.D., "Studies of the Influence of Density on Jet Noise," J. Sound and Vibration, 28(4), pp. 649-668, 1973.

15. Ahuja, K.K., and Bushell, K.W., "An Experimental Study of Subsonic Jet Noise and Comparison with Theory," J. Sound and Vibration, 30(3), pp. 317-341, 1973.

16. Tanna, H.K., “An Experimental Study of Jet Noise, Part I: Turbulent Mixing Noise." J. Sound and Vibration, 50(3), pp. 405-428, 1977.

17. Tanna, H.K., “An Experimental Study of Jet Noise, Part II: Shock Associated Noise." J. Sound and Vibration, 50(3), pp. 429-444, 1977.

18. Bates, D.M., and Watts, D.G., Nonlinear Regression Analysis and its Applications, John Wiley \& Sons, 1988.

19. Bridges, J., and Wernet, M.P., "Turbulence Associated with Broadband Shock Noise in Hot Jets," AIAA Paper 2008-2834, May, 2008.

20. Tam, C.K.W., and Tanna, H.K., "Shock Associated Noise of Supersonic Jets from ConvergentDivergent Nozzles," J. Sound and Vibration, 81(3), pp. 337-358, 1982.

21. Seiner, J.M., and Norum, T.D., "Experiments on Shock Associated Noise of Supersonic Jets," AIAA Paper 79-1526, 1979.

22. Seiner, J. M., and Norum, T. D., "Aerodynamic Aspects of Shock Containing Jet Plumes," AIAA Paper 80-0965, 1980.

23. Norum, T.D., and Seiner, J.M., "Measurements of Mean Static Pressure and Far Field Acoustics of Shock-Containing Supersonic Jets," NASA TM-84521, 1982.

24. Harper-Bourne, M., and Fisher, M.J., "The Noise from Shockwaves in Supersonic Jets," Proceedings (No. 131) of the AGARD Conference on Noise Mechanisms, Brussels, Belgium, 1973.

25. Tam, C.K.W., "Broadband Shock Associated Noise of Moderately Imperfectly Expanded Supersonic Jets," J. Sound and Vibration, 140(1), pp. 55-71, 1990.

26. Viswanathan, K., Alkislar, M., and Czech, M., "Characteristics of the Shock Noise Component of Jet Noise," AIAA Paper 2008-2835, 2008.

27. Zaman, K.B.M.Q., Bridges, J.E., and Brown, C.A., "An Excess Broadband Noise Observed with Overexpanded Jets,” AIAA Paper 2009-289, January, 2009. 


\begin{tabular}{|c|c|c|}
\hline \multicolumn{2}{|c|}{ REPORT DOCUMENTATION PAGE } & $\begin{array}{l}\text { Form Approved } \\
\text { OMB No. 0704-0188 }\end{array}$ \\
\hline \multicolumn{3}{|c|}{ 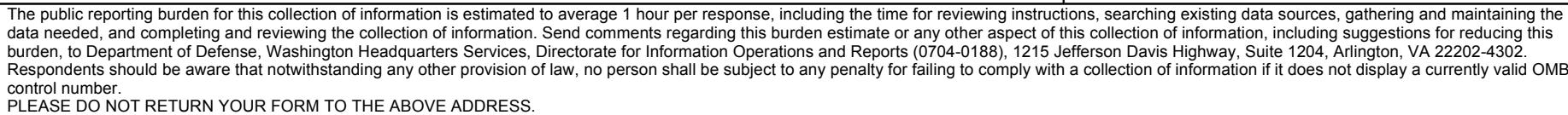 } \\
\hline $\begin{array}{l}\text { 1. REPORT DATE (DD-MM-YYYY) } \\
01-10-2009\end{array}$ & $\begin{array}{l}\text { 2. REPORT TYPE } \\
\text { Technical Memorandum }\end{array}$ & 3. DATES COVERED (From - To) \\
\hline \multirow{3}{*}{\multicolumn{2}{|c|}{$\begin{array}{l}\text { 4. TITLE AND SUBTITLE } \\
\text { Development of Jet Noise Power Spectral Laws Using SHJAR Data }\end{array}$}} & 5a. CONTRACT NUMBER \\
\hline & & 5b. GRANT NUMBER \\
\hline & & 5c. PROGRAM ELEMENT NUMBER \\
\hline \multirow{3}{*}{\multicolumn{2}{|c|}{$\begin{array}{l}\text { 6. AUTHOR(S) } \\
\text { Khavaran, Abbas; Bridges, James }\end{array}$}} & 5d. PROJECT NUMBER \\
\hline & & 5e. TASK NUMBER \\
\hline & & $\begin{array}{l}\text { 5f. WORK UNIT NUMBER } \\
\text { WBS 561581.02.08.03.18.02 }\end{array}$ \\
\hline \multicolumn{2}{|c|}{$\begin{array}{l}\text { 7. PERFORMING ORGANIZATION NAME(S) AND ADDRESS(ES) } \\
\text { National Aeronautics and Space Administration } \\
\text { John H. Glenn Research Center at Lewis Field } \\
\text { Cleveland, Ohio 44135-3191 }\end{array}$} & $\begin{array}{l}\text { 8. PERFORMING ORGANIZATION } \\
\text { REPORT NUMBER } \\
\text { E-17036 }\end{array}$ \\
\hline \multirow{2}{*}{\multicolumn{2}{|c|}{$\begin{array}{l}\text { 9. SPONSORING/MONITORING AGENCY NAME(S) AND ADDRESS(ES) } \\
\text { National Aeronautics and Space Administration } \\
\text { Washington, DC 20546-0001 }\end{array}$}} & $\begin{array}{l}\text { 10. SPONSORING/MONITOR'S } \\
\text { ACRONYM(S) } \\
\text { NASA }\end{array}$ \\
\hline & & $\begin{array}{l}\text { 11. SPONSORING/MONITORING } \\
\text { REPORT NUMBER } \\
\text { NASA/TM-2009-215674; AIAA-2009- } \\
3378\end{array}$ \\
\hline \multicolumn{3}{|c|}{$\begin{array}{l}\text { 12. DISTRIBUTION/AVAILABILITY STATEMENT } \\
\text { Unclassified-Unlimited } \\
\text { Subject Category: } 07 \\
\text { Available electronically at http://gltrs.grc.nasa.gov } \\
\text { This publication is available from the NASA Center for AeroSpace Information, 443-757-5802 }\end{array}$} \\
\hline
\end{tabular}

\section{SUPPLEMENTARY NOTES}

\section{ABSTRACT}

High quality jet noise spectral data measured at the Aeroacoustic Propulsion Laboratory at the NASA Glenn Research Center is used to examine a number of jet noise scaling laws. Configurations considered in the present study consist of convergent and convergent-divergent axisymmetric nozzles. Following the work of Viswanathan, velocity power factors are estimated using a least squares fit on spectral power density as a function of jet temperature and observer angle. The regression parameters are scrutinized for their uncertainty within the desired confidence margins. As an immediate application of the velocity power laws, spectral density in supersonic jets are decomposed into their respective components attributed to the jet mixing noise and broadband shock associated noise. Subsequent application of the least squares method on the shock power intensity shows that the latter also scales with some power of the shock parameter $\left(\mathrm{M}^{2}{ }_{\mathrm{j}}-\mathrm{M}_{\mathrm{d}}^{2}\right)$. A modified shock parameter is defined in order to reduce the dependency of the regression factors on the nozzle design point within the uncertainty margins of the least squares method.

\section{SUBJECT TERMS}

Noise; Aircraft noise; Aerodynamic noise; Acoustics

\begin{tabular}{|c|c|c|c|c|c|}
\hline \multicolumn{3}{|c|}{ 16. SECURITY CLASSIFICATION OF: } & \multirow{2}{*}{$\begin{array}{l}\text { 17. LIMITATION OF } \\
\text { ABSTRACT } \\
\text { UU }\end{array}$} & \multirow{2}{*}{$\begin{array}{l}\text { 18. NUMBER } \\
\text { OF } \\
\text { PAGES } \\
27\end{array}$} & \multirow{2}{*}{$\begin{array}{l}\text { 19a. NAME OF RESPONSIBLE PERSON } \\
\text { STI Help Desk (email:help@sti.nasa.gov) } \\
\text { 19b. TELEPHONE NUMBER (include area code) } \\
\text { 443-757-5802 }\end{array}$} \\
\hline $\begin{array}{l}\text { a. REPORT } \\
U\end{array}$ & $\begin{array}{l}\text { b. ABSTRACT } \\
U\end{array}$ & $\begin{array}{l}\text { c. THIS } \\
\text { PAGE } \\
\text { U }\end{array}$ & & & \\
\hline
\end{tabular}



